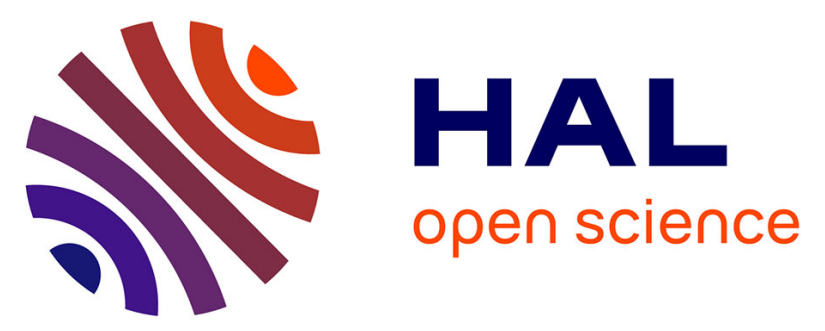

\title{
How relevant are local climate zones and urban climate zones for urban climate research? Dijon (France) as a case study.
}

\author{
Yves Richard, Justin Emery, Julita Dudek, Julien Pergaud, Carmela \\ Chateau-Smith, Sébastien Zito, Mario Rega, Thibaut Vairet, Thierry Castel, \\ Thomas Thévenin, et al.
}

\section{To cite this version:}

Yves Richard, Justin Emery, Julita Dudek, Julien Pergaud, Carmela Chateau-Smith, et al.. How relevant are local climate zones and urban climate zones for urban climate research? Dijon (France) as a case study.. Urban Climate, 2018, 26, pp.258-274. 10.1016/j.uclim.2018.10.002 . hal-01918945

\section{HAL Id: hal-01918945 \\ https://hal.science/hal-01918945}

Submitted on 22 Jul 2019

HAL is a multi-disciplinary open access archive for the deposit and dissemination of scientific research documents, whether they are published or not. The documents may come from teaching and research institutions in France or abroad, or from public or private research centers.
L'archive ouverte pluridisciplinaire HAL, est destinée au dépôt et à la diffusion de documents scientifiques de niveau recherche, publiés ou non, émanant des établissements d'enseignement et de recherche français ou étrangers, des laboratoires publics ou privés. 


\title{
How relevant are local climate zones and urban climate zones for urban climate research? Dijon (France) as a case study
}

\author{
Yves Richard $^{\mathrm{a}, *}$, Justin Emery ${ }^{\mathrm{b}}$, Julita Dudek ${ }^{\mathrm{c}}$, Julien Pergaud ${ }^{\mathrm{a}}$, \\ Carmela Chateau-Smith ${ }^{\mathrm{d}}$, Sébastien Zito ${ }^{\mathrm{a}}$, Mario Rega ${ }^{\mathrm{a}}$, Thibaut Vairet ${ }^{\mathrm{b}}$, \\ Thierry Castel ${ }^{\mathrm{a}, \mathrm{e}}$, Thomas Thévenin ${ }^{\mathrm{b}}$, Benjamin Pohl ${ }^{\mathrm{a}}$ \\ ${ }^{a}$ Centre de Recherches de Climatologie, UMR 6282 Biogéosciences, CNRS/Univ Bourgogne Franche-Comté, France \\ ${ }^{\mathrm{b}}$ UMR 6049 THEMA, CNRS/Univ Bourgogne Franche-Comté, France \\ ${ }^{\mathrm{c}}$ UMR 5600 Environnement Ville Société, CNRS/Univ Lyon III, France \\ ${ }^{\mathrm{d}}$ UFR SVTE/Univ Bourgogne Franche-Comté, France \\ ${ }^{\mathrm{e}}$ AgroSUP Dijon, France.
}

\section{A R T I C L E I N F O}

\section{Keywords:}

Urban heat Island

Urban climate zone

Local climate zone

ANOVA

WRF

MUSTARDijon network

\begin{abstract}
A B S T R A C T
Several typologies of urban surface properties have been proposed, in recent years, for urban heat island studies and climate modeling. Some were specifically developed for cities and urban climate issues, like the Urban Climate Zones, and the more recent Local Climate Zones. The initial objective of this paper is to evaluate the capacity of these two typologies to identify thermal environments in and around cities, and to determine which typology best captures the daily spatio-temporal patterns of surface and urban canopy heat islands. To simulate urban climate with a model, LULC data based on a given typology are required. To avoid circularity, we combined the Corine Land Cover database, with data for the whole of Europe, and the BD TOPO database, for France, to form a new tool, CLC_USGS, which we used as input for the WRF limitedarea model, with a 150-m grid resolution. The capacity of each typology to identify coherent thermal zones was estimated for Dijon, a medium-sized French city, during a three-week heat wave, over a 24-hour period, in conditions favorable to urban heat island development. The comparison was based on hourly air temperatures directly output from the WRF model, those obtained from the purpose-built MUSTARDijon 47-sensor meteorological network, and NDVI values and land surface temperatures estimated from Landsat images for 11 July 2015 at 1030 UTC. Typical diurnal variations and spatial contrasts of surface and air temperatures were identified in both simulations and observations. As both typologies show significant capacity for identifying thermally coherent intra-urban areas, this study suggests that they could both be useful for urban climate applications. The typology that is most generally applicable in worldwide contexts is Local Climate Zones.
\end{abstract}

\section{Introduction}

Urbanization and urban expansion linked to demographic growth produce diverse mosaics of built and non-built surfaces. This diversity results in very different surface energy budgets and Urban Heat Island (UHI) effects, induced by impermeable, heat-storing

\footnotetext{
* Corresponding author.

E-mail address: yves.richard@u-bourgogne.fr (Y. Richard).
} 
building materials. Even though air temperature at any given point depends primarily on large-scale atmospheric dynamics, it can also be significantly influenced by differences in surface properties, and their associated effects on the energy budget. This phenomenon of warmer temperatures in cities compared to nearby rural areas (UHI), can be observed at different levels (see Arnfield, 2003, for a review): in the surface temperature (referred to as Surface Urban Heat Island: SUHI), in the $2 \mathrm{~m}$ near-surface air temperature (Urban Canopy Layer Urban Heat Island: UCL-UHI), and in the temperature above roof level (Urban Boundary Layer Urban Heat Island, UBL-UHI). Such marked temperature contrasts only develop if and when the synoptic wind is weak or disorganized enough to let the differences between "urban/artificial" and "rural/natural" surface properties be expressed in the temperature fields of a given urbanized area (Lemonsu and Masson, 2002). Now that the historical urban vs. rural dichotomy (Stewart, 2007) has been progressively smoothed by urbanization and urban sprawl at the city outskirts, the new challenge for applied atmospheric science is both thematic and methodological. Applied sciences must help city planners to optimize urban microclimates by choosing patterns of built and non-built surfaces best adapted to improve the quality of life and well-being in cities (i.e. air quality, outdoor thermal comfort, etc.). Applied atmospheric sciences must also develop methods to capture inter-urban and intra-urban variations to better assess microclimate variations in and around cities. Taking into account the dilution processes of urbanization, it is ever more important to measure how relevant existing land surface categories are for urban climate studies today.

Urban climate is a complex, yet quite recent issue. The first attempt to relate air temperature to Land-Use/Land-Cover (LULC) surface properties was made in the Greater London area (Chandler, 1962). Since then, a generic typology defined in 2004 has been put forward as a worldwide standard for urban areas by the World Meteorological Organization (Oke, 2006). It divides city terrain into seven homogeneous groups, the Urban Climate Zones (UCZs), ranging from semi-rural to intensely developed sites. The aim of the UCZ typology was not to provide a detailed description of each urban site, but rather the identification of coherent "districts", in terms of their capacity to modify the local climate (Oke, 2006). Although classifying urban areas is a vital preliminary step in urban climate studies, a systematic UHI literature review (Stewart, 2011) found that more than three-quarters of observational UHI studies gave no quantitative metadata of site exposure or LULC, often opting for the simpler urban vs. rural dichotomy. Stewart and Oke (2012) therefore proposed Local Climate Zones (LCZs) as a new typology to standardize definitions of urban and rural sites for observational UHI studies.

Despite recent progress in satellite imagery, differentiating urban structures and morphologies from the same data input is still a challenging task (Bechtel et al., 2015). As climatic parameters depend on elevation and land use, climate analysis requires highresolution spatial digital data (Baumüller, 2015). Initiated in 2012 at the ICUC8 meeting in Dublin (Feddema et al., 2015), the World Urban Database and Portal Tool (WUDAPT) was intended as an international collaborative project for the acquisition, storage, and dissemination of climate-relevant data about the physical properties of cities worldwide (Mills et al., 2015).

To test the relative capacity of UCZ and LCZ to identify contrasting thermal environments in and around cities, this case study focuses on Dijon, a medium-sized European city (Giffinger et al., 2007). The CLC_USGS, a tool coherent with USGS categories, combining data from Corine Land Cover (CLC), a database supported by the European Union (Büttner et al., 2002), and BD TOPO, a French database (IGN, 2016), was constructed to provide input for the WRF model. Using CLC_USGS as model input will avoid bias when comparing UCZ and LCZ. Air temperature data from two complementary but independent sources (in situ measurements and climate modeling) were used to test the efficiency of the typologies. The analysis focused on air temperature developing over a 24$\mathrm{h}$ cycle, during a summer day favorable to UHI development. Surface temperature data from a Landsat satellite image completed the analysis.

This paper is organized as follows: Section 2 briefly explains the relevance of working on a medium-sized city in a European context, and describes the Dijon area. The two typologies (LCZ and UCZ) and CLC_USGS are developed from a varying number of LULC groups. The temperatures analyzed here are air temperatures obtained from the purpose-built MUSTARDijon urban meteorological network, and from a numerical climate simulation, completed by surface temperature obtained from satellite images. In Section 3, the capacity of LCZ, UCZ, and CLC_USGS to discriminate temperature patterns is assessed. The respective limitations and strengths of the two typologies are discussed in Section 4, together with perspectives for future research.

\section{Material and method}

This study focuses on Dijon, a medium-sized European city, described in Section 2.1. The databases and Geographic Information System (GIS) process used to elaborate the two typologies (LCZ and UCZ) and CLC_USGS (Fig. 1), are presented in Section 2.2. The production of environmental variables, based on data from satellite images, in situ measurements, and numerical simulations, is described in Section 2.3 (Fig. 1). The statistical methods used to analyze the relationships between the typologies and the environmental variables are presented in Section 2.4.

\subsection{The Dijon urban area as a case study}

Attention is often focused on mega-cities, yet smaller cities may also be of great importance. In Europe, almost half of the urban population (44\%) lives in medium-sized cities (Giffinger et al., 2007). Such cities can be dramatically impacted by heat waves, as demonstrated in 2003, when Dijon was second only to Paris in terms of excess mortality (Vandentorren et al., 2004). Between August 1 and August 19, 2003, the excess mortality rate for Dijon was 93\%, compared with the same period in $1999-2002$ (Vandentorren et al., 2004). Between August 5 and August 15, 2003, the excess mortality rate for Dijon reached 179\% (Wahl et al., 2005). Considering that heat waves will increase during the coming decades due to climate change (Willett and Sherwood, 2012), and that UHIs may well exacerbate their impact, characterizing UHIs in medium-sized cities becomes a pressing issue in terms of public health. 


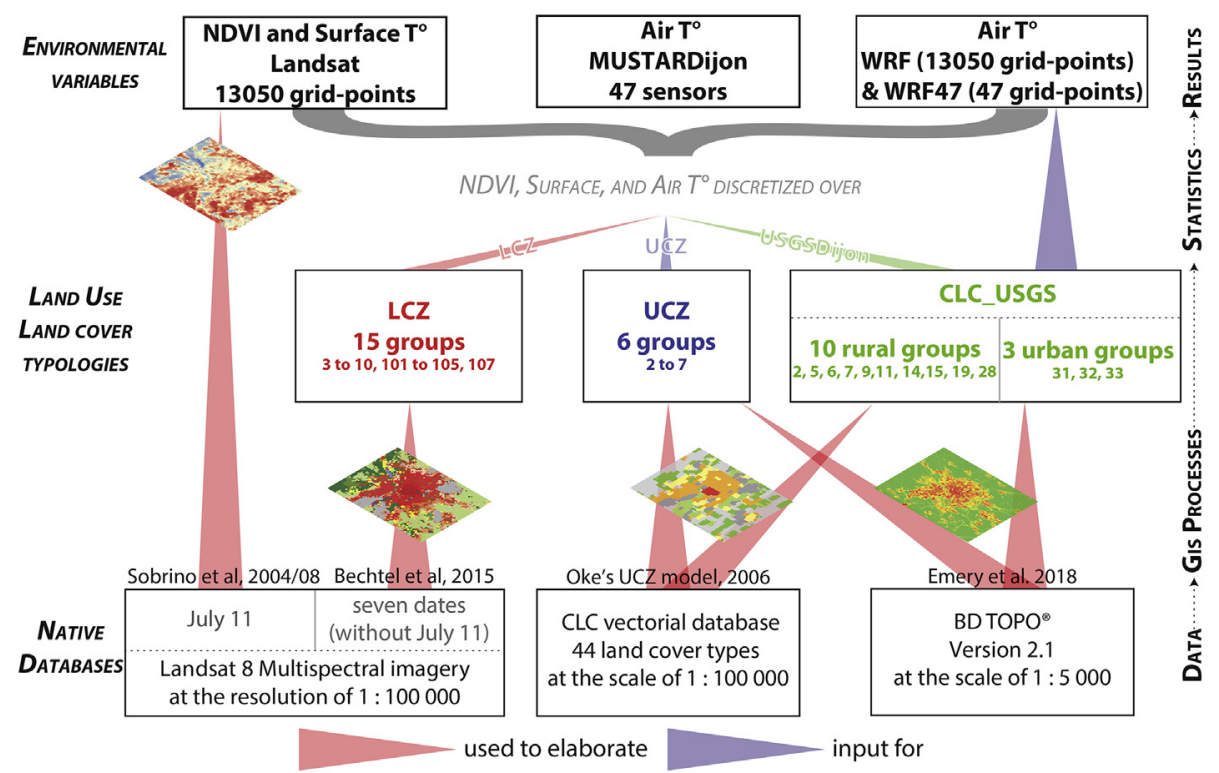

Fig. 1. Workflow: from data, to GIS process, statistics, and results.

With about 238,000 inhabitants in 2011 (Thierry, 2015), Dijon is a medium-sized European urban area located in northeastern France. Dijon is monocentric, with extensive agriculture (indicated by the geometric plot) in the plain to the east, while forests are prevalent to the west, with a plateau reaching $600 \mathrm{~m}$ in altitude (Fig. 2). Dijon is classed Cfb in the updated Köppen-Geiger climate (Kottek et al., 2006), which means Warm Temperate (C), fully humid (f), with a warm summer (b). The average annual temperature is around $11^{\circ} \mathrm{C}$, with high interannual variability (Joly et al., 2010).

We here attempt to apply two urban typologies to Dijon, France, UCZ and LCZ. Considered as the latest urban typology for climate studies (Leconte et al., 2016), LCZs have generally been used for cities of over one million inhabitants, e.g. Glasgow (Emmanuel and Krüger, 2012), Hong Kong (Lau et al., 2015; Zheng et al., 2018), Madrid (Brousse et al., 2016), and for a comparison of eight cities (Beijing, Chicago, Hong Kong, Khartoum, Lisboa, Madrid, Milano, and Sao Paulo) from five continents (Bechtel et al., 2016). The LCZ typology is now also used for smaller cities: Colombo, Sri Lanka (Perera and Emmanuel, 2016); Szeged, Hungary (Gál et al., 2015); Olomouc, Czech Republic (Lehnert et al., 2015); and Nancy, France (Leconte et al., 2015a, 2015b).

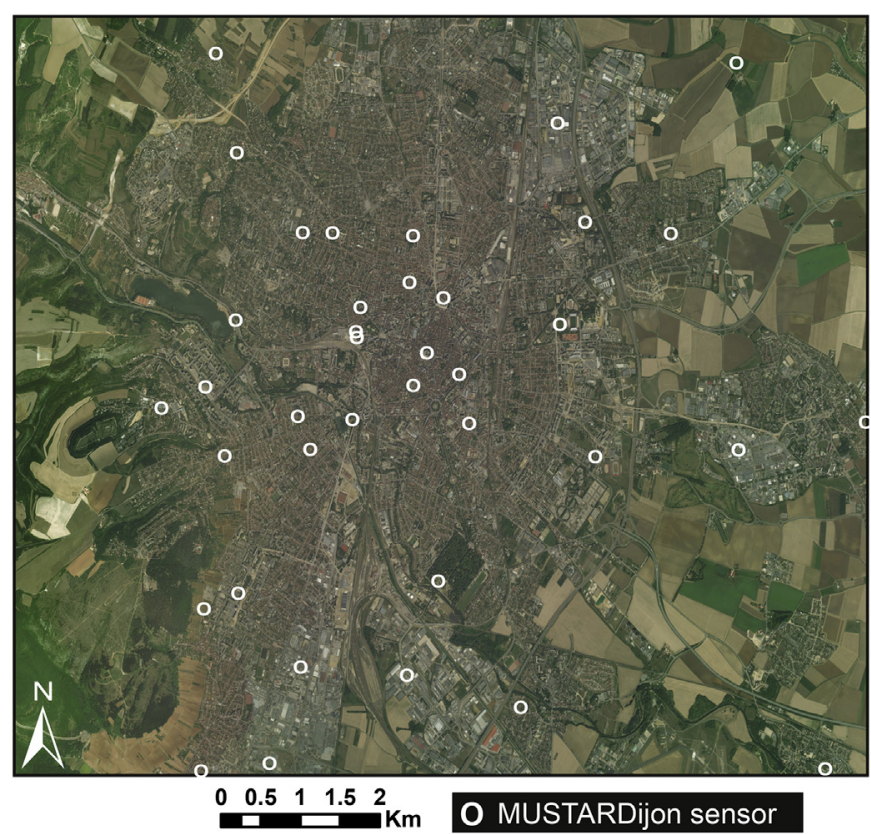

Fig. 2. Study area (Google satellite image), showing MUSTARDijon network. 
With climate change, in France (Ouzeau et al., 2016), and more generally in Europe (Schoetter et al., 2015), we expect more frequent, longer, more intense heat waves. In this study, taking into account data availability and the meteorological conditions favorable to UHIs, the focus is on July 2015, marked by two heat waves with many record values, within a three-week period. More specifically, particular attention is paid to July 11, a cloud-free day for which Landsat images are available (Section 2.3.1).

\subsection{From data to typologies}

The three native databases selected for this study are available in many formats, at different resolutions (Fig. 1). The spatial extent of the study area centered on Dijon is shown in Fig. 2. At a resolution of $150 \mathrm{~m}$ (see Section 2.3.3), the grid for the study area is composed of 13,050 grid-points (Fig. 3). The two typologies and the CLC_USGS tool are presented in the following three subsections, together with the data and GIS process used to produce them.

\subsubsection{Mapping Local Climate Zones (LCZs) over the Dijon urban area}

The WUDAPT method (Bechtel and Daneke, 2012; Stewart and Oke, 2012; Brousse et al., 2016) relies on the semi-automatic classification of satellite image irradiances to identify LCZs, based on user-defined training areas digitized with Google Earth software, each containing an LCZ of a particular type. Semi-automatic classification remains subjective not only because each user will define training areas based on individual "insider knowledge", but also because of the choice of seasons used for Landsat images. To ensure worldwide applicability, the LCZ typology and WUDAPT methodology use free-of-charge Google Earth and Landsat 8 satellite images (available from USGS Earth Explorer, https://earthexplorer.usgs.gov/). Following Bechtel et al. (2015), we used multispectral and thermal data from different seasons. Here we used Landsat 8 data for seven dates (23 September 2013, 11 April 2015, 19 July 2015, 14 August 2016, 30 August 2016, 2 January 2017, and 8 March 2017). The LCZ typology applied to Dijon (the level 0 product in WUDAPT) was generated using software and tools from the System for Automated Geoscientific Analyses (SAGA; Conrad et al., 2015; Figs. 1 and 3a). Gál et al. (2015) have shown that the highly data-intensive GIS method produces LCZ maps that are only slightly different from those produced with the globally applicable satellite method. In a case study of Hong Kong, the WUDAPT method classified land cover types more accurately than the GIS-based method, which detected more details (Wang et al., 2018). Furthermore, WUDAPT level 0 data can be used as input data for mesoscale weather and climate modeling (Brousse et al., 2016; Wang et al., 2018).

\subsubsection{Adapting Urban Climate Zones (UCZs) to the Dijon urban area}

As the UCZ typology was originally developed for North American cities (Oke, 2006), several modifications were necessary to adapt it to the European context. The original method of Grimmond and Oke (1999), and then Oke (2006), required three criteria: roughness (which assesses the impact of 3D obstacles on wind flow), aspect ratio (or street height-to-width ratio, $\mathrm{H} / \mathrm{W}$ ), and the percentage of built (or impermeable) surfaces. The roughness criterion was based on the Davenport classification (Davenport et al., 2000). As the data used for the Davenport classification are unavailable, we aligned six UCZs with the three urban CLC categories present in Dijon, while the seventh UCZ corresponds to other, non-urban CLC categories (Table 1).

Following Houet and Pigeon (2011), the aspect ratio was calculated as the ratio between the cumulative surface of all walls in the area and the cumulative ground surface of all buildings. The geographic BD TOPO database Version 2.1 (IGN, 2016), as described in Emery et al. (2018), was used for this task, and also to calculate the impermeable ratio: percent (built + roads + sidewalks-vegetation). Dijon is characterized by a city center with low buildings (low aspect ratio values) but with a very high percentage of impermeable surfaces (Fig. 4). Hence, lower aspect ratio thresholds were used for UCZs 2, 3, 6, and 7 (Table 1). The final adaptation was to raise the upper threshold of percent built for UCZs 3 and 6.

After applying this method with QGIS, $>58 \%$ of the grid-points (7602 of the 13,050) remained unassigned. This problem can partly be explained by the choice of high-resolution $150 \mathrm{~m}$ grid-points: even in urban areas, aspect ratio and percent built values from BD TOPO may fall below threshold limits for some grid-points (Table 1). This vectorial dataset focuses more on urban (e.g. buildings and transport infrastructures), than on rural elements, with no detailed vectorial description for suburban areas or agricultural areas.

To improve grid-point assignment, a moving window (focal treatment) of 9 grid-points (8 closest neighbors) was used to attribute a UCZ group to the each of the remaining unassigned grid-points, based on the mode (or most frequently observed group within the window). This focal treatment classified most of the unassigned grid-points, with some spatial smoothing of geographic information. The remaining non-classified grid-points (NC) are mostly located at the periphery of the Dijon urban area (Fig. 3b).

\subsubsection{Combining CLC and BD TOPO to fit USGS for use with WRF}

For urban climate modeling, land-use information must be at high resolution. The resolution of the LULC database provided with the Weather and Research Forecasting (WRF) model (Skamarock and Coauthors, 2008) is too coarse (about $1 \mathrm{~km}$ ) for urban climate studies (Chen et al., 2011). The CLC and BD TOPO databases used to adapt USGS LULC to the Dijon context also provided the highresolution data required to fit the 33 USGS LULC categories to the WRF model. The European CLC database, with 44 land-cover categories available at a 250-m resolution (Büttner et al., 2002), was used to refine the USGS partitioning. The spatial boundaries are inherited from CLC and the attribute physical variables (roughness, emissivity, Leaf Area Index, and albedo) are inherited from the USGS categories. The resulting hybrid database is referred to as the CLC_USGS tool.

Nine rural groups (2, 5, 6, 7, 9, 11, 14, 15, and 19; Fig. 1) among the 24 standard USGS LULC categories were identified using CLC data. The tenth group (28) corresponds to inland water bodies (Kir Lake; Fig. 3c). Within the urban area identified by CLC spatial boundaries, morphological parameters from BD TOPO were used to calculate the input parameters for WRF. As the Urban Canopy 
(a)

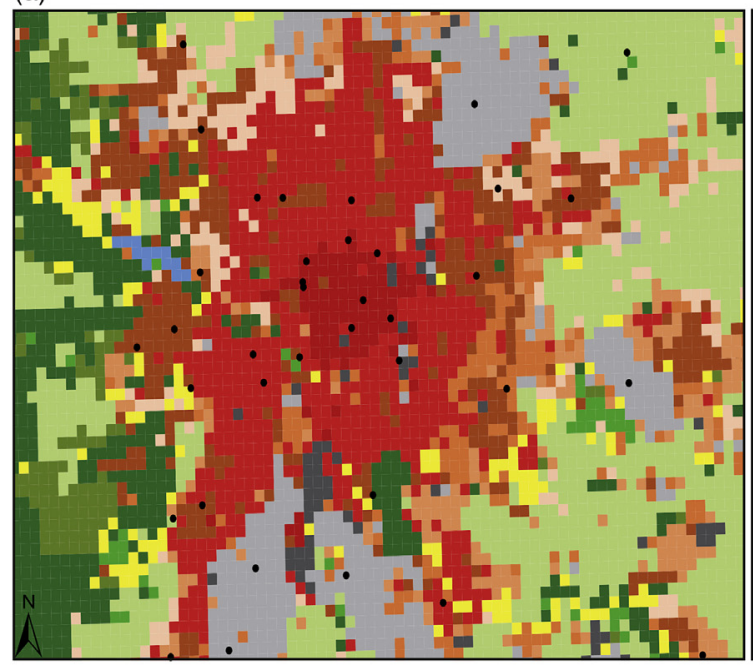

(b)

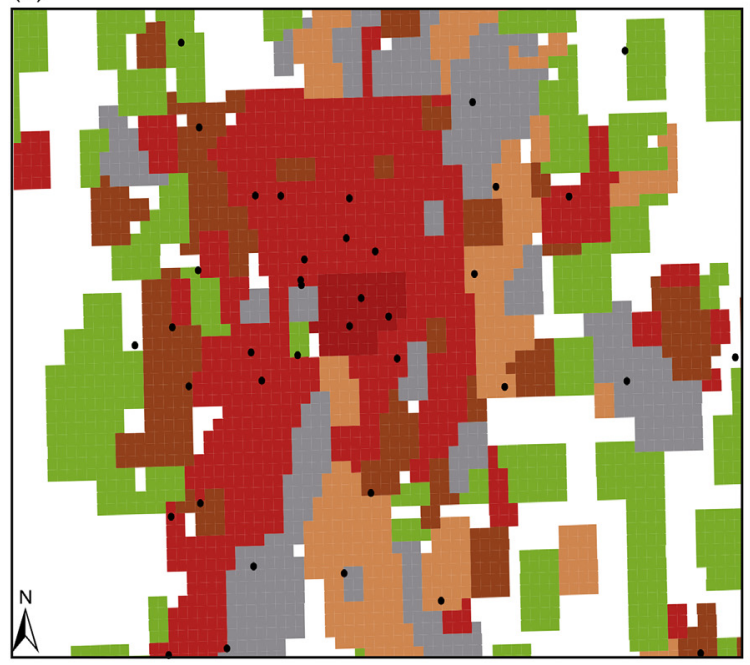

(c)

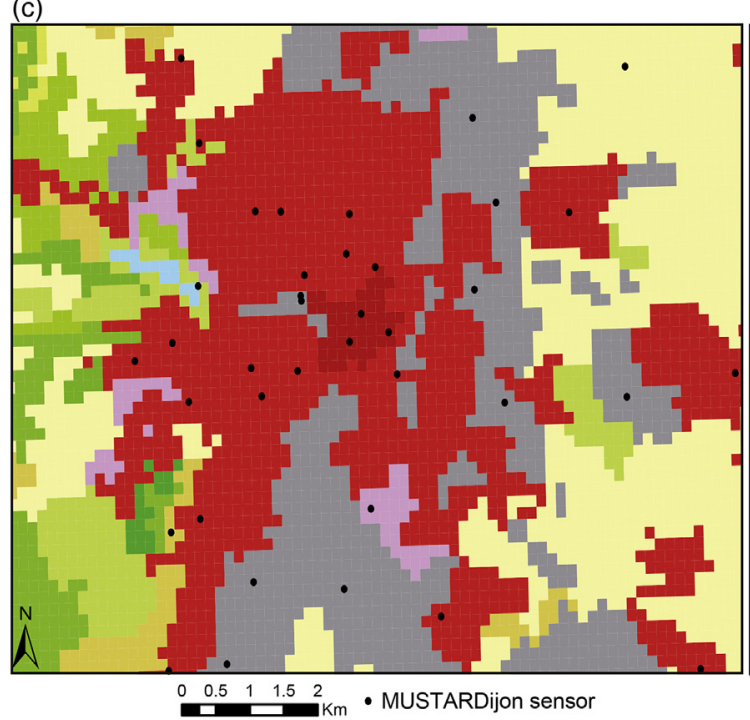

Local Climate Zones

(LCZ - Stewart and Oke, 2012)

LCZ2 Compact mid-rise

LCZ3 Compact low-rise

LCZ4 Open high-rise

LCZ5 Open mid-rise

LCZ6 Open low-rise

LCZ7 Lightweight low-rise

LCZ8 Large low-rise

LCZ9 Sparsely built

LCZ10 Heavy industry

LCZA101 Dense trees

LCZB/102 Scattered trees

LCZCH03 Bush, scrub

LCZD/104 Low plants

LCZE/105 Bare rock or paved

LCZG/107 Water

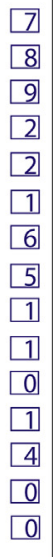

Urban Climate Zones

(UCZ - Oke, 2006)

\begin{tabular}{|l|l}
\hline NC & Non-Classified grid-point \\
\hline
\end{tabular}

UCZ2 Intensely developed High density

Uc73 Highly developed

UCZ3 Medium density

UCZ4 Highly developed (Activity) -

UCZ4 Low or medium density

UCZ5 Medium development

UCZ6 6 Mixed

UCZ7 Semi-rural development 
Table 1

UCZ for Dijon (adapted from Oke, 2006).

\begin{tabular}{|c|c|c|c|c|c|c|}
\hline & \multicolumn{2}{|l|}{ Roughness } & \multicolumn{2}{|c|}{$\begin{array}{c}\text { Aspect Ratio } \\
\text { (Height-to-Width (H/W)) }\end{array}$} & \multicolumn{2}{|c|}{$\begin{array}{c}\text { Percent built } \\
\text { (impermeable) }\end{array}$} \\
\hline UCZ & $\begin{array}{c}\text { Davenport } \\
\text { classification }\end{array}$ & $\begin{array}{c}\text { Adapted } \\
\text { classification }\end{array}$ & Oke threshold & Adapted threshold & Oke threshold & Adapted threshold \\
\hline unavailable & $\begin{array}{c}\text { CLC } \\
\text { categories }\end{array}$ & $\begin{array}{c}\text { N. American } \\
\text { context }\end{array}$ & BD TOPO data & $\begin{array}{c}\text { N. American } \\
\text { context }\end{array}$ & BD TOPO data \\
\hline 1 & 8 & CUF & $>2$ & $>2$ & $>90$ & $>90$ \\
\hline 2 & 7 & CUF & $1.0-2.5$ & $0.5-2.5$ & $>85$ & $>85$ \\
\hline 3 & 7 & DUF or CUF & $0.5-1.5$ & $0.15-1.5$ & $70-85$ & $70-95$ \\
\hline 4 & 5 & ICU & $0.05-0.2$ & $0.05-0.2$ & $70-95$ & $70-95$ \\
\hline 5 & 6 & DUF & $0.2-0.6$ & $0.2-0.6$ & $35-65$ & $35-65$ \\
\hline 6 & 5 & DUF, CUF & $0.1-0.5$ & $0.05-0.5$ & $<40$ & $<55$ \\
\hline 7 & 4 & others & $>0.05$ & $>0.02$ & $<10$ & $<10$ \\
\hline
\end{tabular}

Black: criterion and threshold as in Oke (2006); Blue: adapted criterion; Red: adapted threshold.

CUF: Continuous urban fabric; DUF: Discontinuous urban fabric; ICU: Industrial or commercial units.

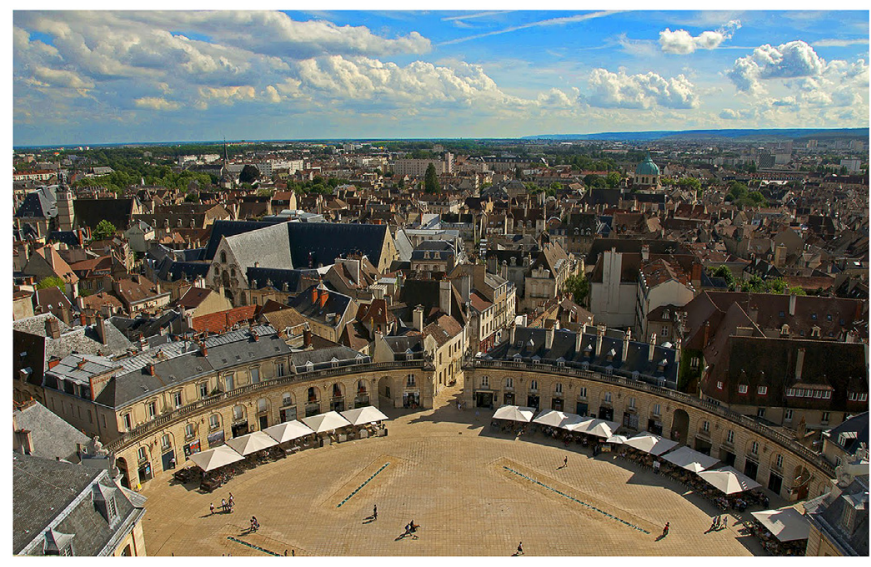

Fig. 4. Historical center with terraced rows of townhouses, but no high-rise buildings. Photo taken from the top of the "Philippe le Bon Tower". (Ville de Dijon).

Model (defined in Kusaka et al., 2001), used in WRF simulations, requires morphological parameters (such as roof width and level, road width, and building size), BD TOPO values were averaged for each urban group, with the method described in Emery et al. (2018).

\subsection{From typology to pattern analysi: three weeks in July 2015, and the case of July 11}

The approaches used to obtain air temperature, and also Land Surface Temperature (LST) and Normalized Difference Vegetation Index (NDVI), are based on (i) satellite images, (ii) in situ measurements, and (iii) numerical simulations (Fig. 1). Remote-sensed NDVI and LST were derived from Landsat images (Fig. 5). Air temperature was obtained from MUSTARDijon in situ measurements and WRF numerical simulations.

\subsubsection{NDVI and LST from Landsat}

For the heat waves during the first three weeks of July 2015, Landsat images of Dijon were available for two dates: July 3 and 11. July 3 corresponds to the peak of the first heat wave, but unfortunately, over Dijon, the sky was partly cloudy for that Landsat scene (1030 UTC). We therefore decided to analyze July 11, a cloud-free day in Dijon, with conditions favorable to UHI development, without wind, sunny and hot, but not corresponding to a heat-wave peak.

Landsat 8 satellite images for 11 July 20151030 UTC were acquired through the Theia server (https://theia-landsat.cnes.fr), where the surface reflectances are already provided. Atmospheric and environmental effects were corrected using the multi-temporal 
(a)

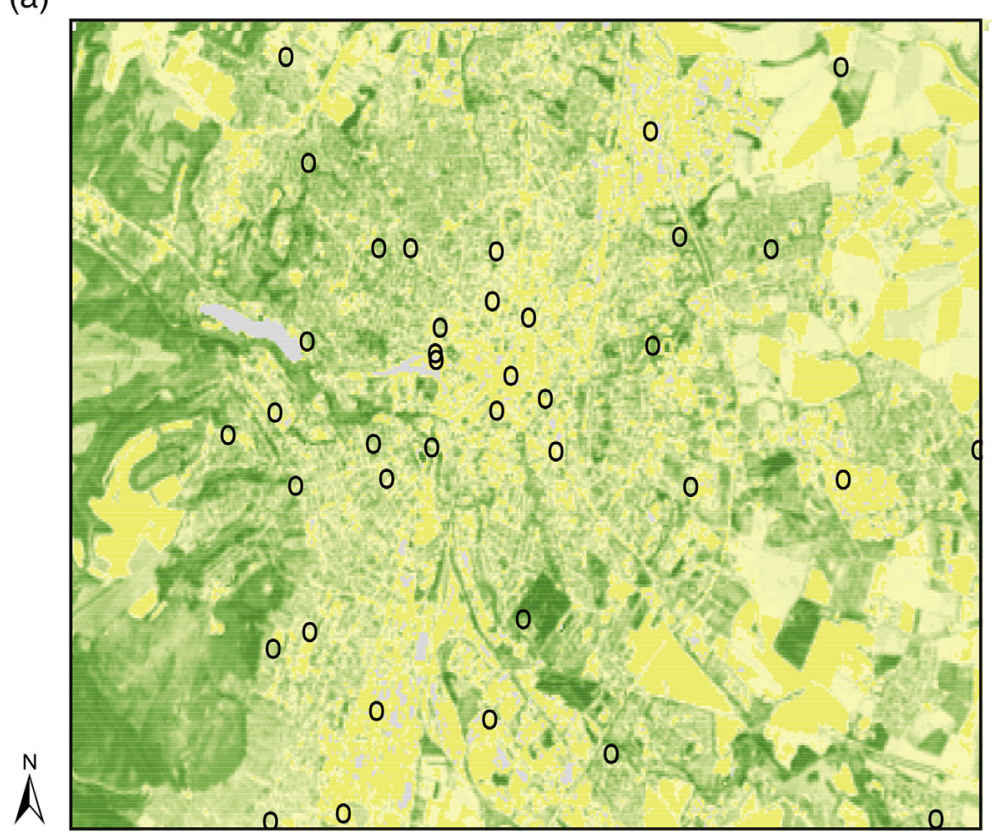

(b)

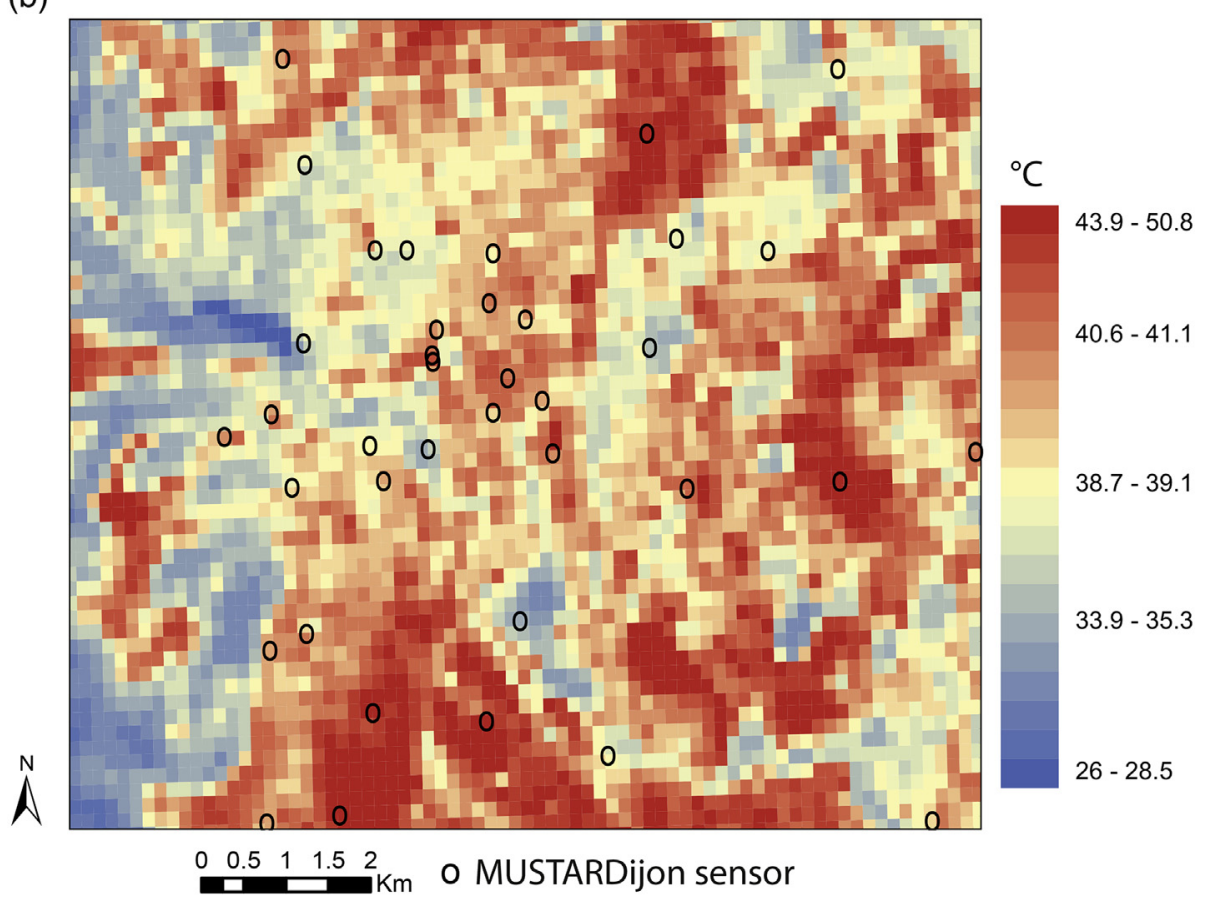

Fig. 5. Landsat 8, 11 July 2015, 1030 UTC: (a) NDVI; (b) Land Surface Temperature (LST).

and multi-spectral method developed by Hagolle et al. (2015), to estimate aerosol optical thickness over land. To ensure independence, this date was not used to determine LCZ (Fig. 1). Three bands, including red, near-infrared and thermal band 10 were used. The red and near-infrared bands were used to calculate NDVI values, then NDVI was used to obtained surface emissivity, while thermal band 10 was used to calculate LST. The LST calculation was based on the Radiative Transfer Equation (RTE), for which thermal radiance (Sobrino et al., 2004, 2008) is used to take into account atmospheric effects and emissivity corrections.

\subsubsection{The MUSTARDijon network of in situ measurements}

Quantifying the intensity and spatial extent of UHIs is challenging because of the paucity and limited spatial resolution of 


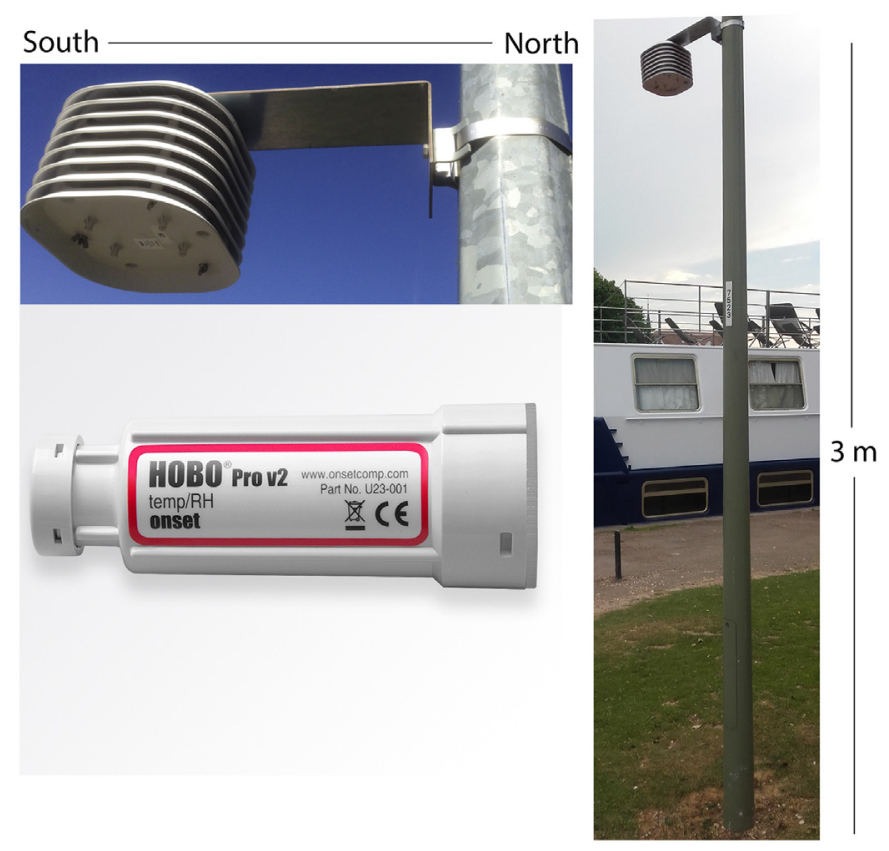

Fig. 6. НОВO U23 Pro v2 sensor, non-aspirated M-RSA Solar Radiation Shield, and a street lamp, with a hose clamp at $3 \mathrm{~m}$ above ground.

traditional air temperature networks in urban areas (Azevedo et al., 2016). High-resolution urban networks must therefore be developed to fill this gap. Two nested spatial scales need to be taken into account: (i) the site, to capture the microclimate, and (ii) the district, to capture the mesoclimate. Insufficient preliminary analysis prior to sensor installation often makes results difficult to transpose and generalize from one study to another (Stewart, 2011).

As in the case of Rotterdam (Van Hove et al., 2015), the Dijon sites were selected after subtracting Digital Elevation Model (DEM) data at surface level from DEM data including buildings, trees and other obstacles. The chosen supports are street lamps. Shadow effects (relief, buildings and trees) were simulated on a geographic information system on March 20 (corresponding to the equinox and therefore to a median requirement in terms of shadows cast) at 0800, 1000, 1200, 1400 and 1600 UTC. All street lamps concerned by such shadow effects between 0800 and 1600 UTC were disregarded. As several hundred street lamps met the required conditions, 47 were selected as follows:

- administrative areas where elected representatives agreed to allow participation in the study;

- zones representing the differences in altitude in and around the agglomeration;

- all seven groups in the UCZ typology.

The 47 HOBO U23 Pro v2 sensors used in this study are identical to those deployed in Athens (Kourtidis et al., 2015). The sensors were placed for one week in crushed ice in a controlled-temperature freezer as a preliminary calibration step, to quantify the uncertainty associated with the instrument. The amplitude thus obtained $\left(0.194^{\circ} \mathrm{C}\right.$, with a minimum of $-0.143{ }^{\circ} \mathrm{C}$ and a maximum of $0.051^{\circ} \mathrm{C}$ ) set the uncertainty limit at $0.2{ }^{\circ} \mathrm{C}$. Each of the sensors was then sheltered within a non-aspirated M-RSA Solar Radiation Shield (Fig. 6), which was then mounted on a street lamp with a hose clamp, $3 \mathrm{~m}$ above ground level on 6 June 2014 (De Lapparent et al., 2015), as recommended by Oke (2006). Instantaneous air temperature (with $+/-0.2^{\circ} \mathrm{C}$ precision for measurements between $0{ }^{\circ} \mathrm{C}$ and $50{ }^{\circ} \mathrm{C}$ ) and relative humidity (2.5\% precision between $10 \%$ and $90 \%$ ) have been recorded every hour since that date. This urban meteorological network (Fig. 2) is hereafter named "Measuring Urban Systems Temperature of Air Round Dijon" (MUSTARDijon). The 47 sensor sites were aligned with the grid-points by spatial join processing (Fig. 3).

\subsubsection{Simulated temperature}

Air temperature was simulated with the Weather and Research Forecasting (WRF) non-hydrostatic, limited-area model (Skamarock and Coauthors, 2008). A limited-area model is nested in a General Circulation Model (Giorgi, 1990). Our setup is adapted to UHI simulations with potential climate applications, which require very high-resolution target data (150 m), but can accept coarser lateral boundary conditions derived from current climate models. The WRF was initialized and forced laterally by ERA-Interim reanalyses (Dee et al., 2011). The simulations were performed according to four one-way nested domains (Fig. 7), with horizontal resolutions at $18,750 \mathrm{~m}, 3750 \mathrm{~m}, 750 \mathrm{~m}$, and finally $150 \mathrm{~m}$ (Domain 4). The one-week spinup for the WRF model began on $23 \mathrm{June}$ 2015 at 0000 UTC. The physical package includes the Kain-Fritsch cumulus scheme (Kain, 2004) for domains 1 and 2 , the Yonsei University parameterization of the planetary boundary layer (Hong et al., 2006) for domains 1 to 3, and the WSM6 scheme for cloud microphysics (Hong et al., 2006). For all domains, we used the Dudhia (1989) shortwave scheme, while the Rapid Radiative Transfer 
(a) Domain 1

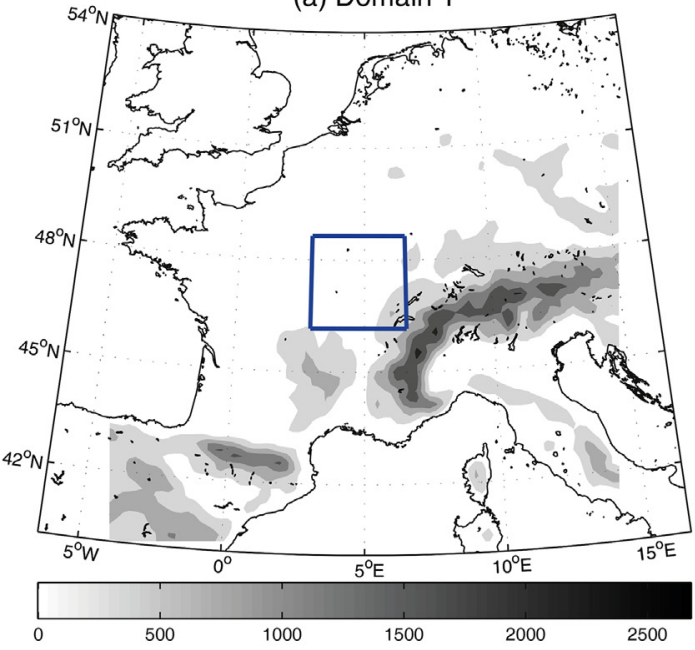

(c) Domain 3

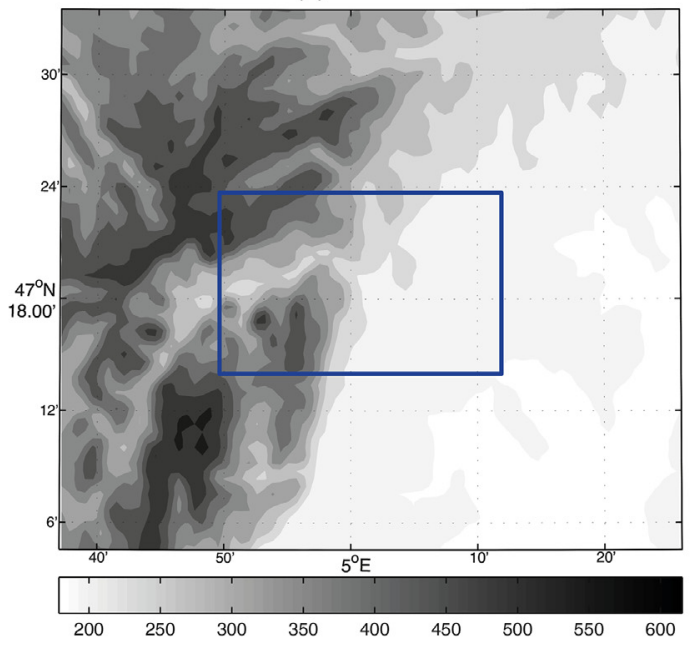

(b) Domain 2

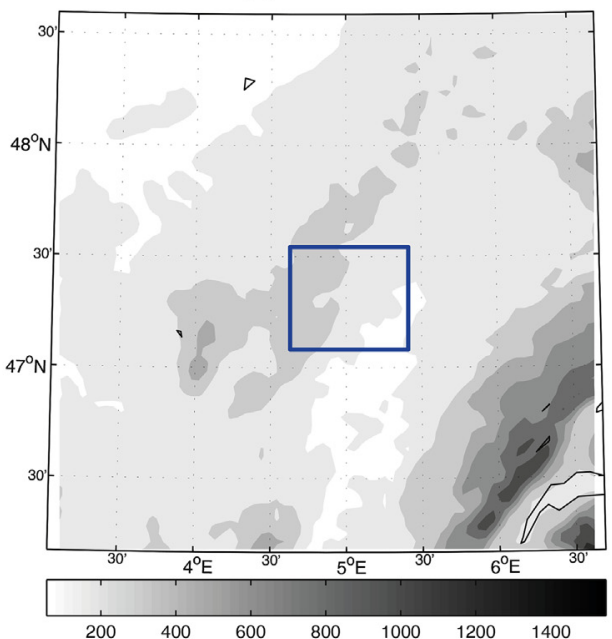

(d) Domain 4

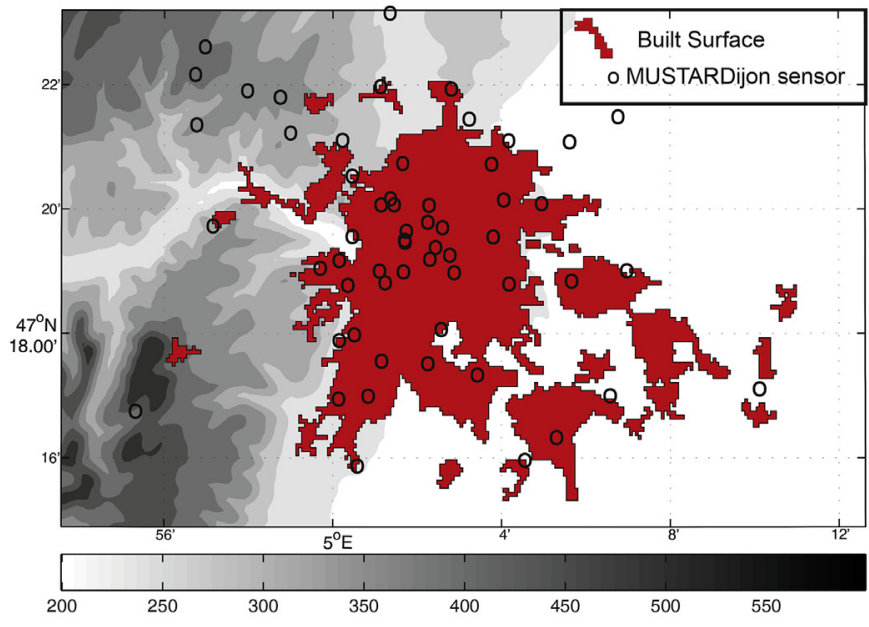

Fig. 7. Nested domains in WRF, with Digital Elevation Model, showing the Dijon urban area (built surface, Domain 4).

Model (Mlawer and Clough, 1997) was used for longwave radiation. Land-atmosphere fluxes were parameterized by the 4-layer NOAH land surface model (Tewari et al., 2004), using CLC_USGS, defined in Section 2.3.3. For Domain 4, the organized turbulence (large eddies) was partly resolved by the dynamics. This implies that no 1D turbulence scheme was activated at this scale: instead, a 3D turbulence based on a 1.5 order TKE closure scheme was used (Skamarock and Coauthors, 2008). The Urban Canopy Model (Chen et al., 2011) was also activated for Domain 4, to simulate the energy exchanges occurring over urban areas. The air temperature values used in this study (WRF T2), were calculated in the surface layer module to represent simulated air temperature at $2 \mathrm{~m}$ above the surface, based on stability functions using similarity theory (Zhang and Anthes, 1982).

\subsection{Statistical analysis: intercomparison of inter-group and intra-group variance}

Our goal is to study the relative capacity of two typologies (LCZ and UCZ) and CLC_USGS to identify thermal environments. How efficient are they at identifying groups that are both homogeneous in terms of thermal environment, and clearly distinct from each other with respect to these same thermal environments? The MUSTARDijon network density, composed of 47 sensors, makes it possible to test this hypothesis statistically. Boxplots allow visual comparison of inter-group and intra-group variance for each of the typologies and each of the environmental variables. To quantify the capacity and test the relevance of these typologies to account for spatial patterns of air temperature variability, we performed a set of 216 analyses of variance (ANOVA). For each typology, an ANOVA was calculated for each of the $24 \mathrm{~h}$. The respective weight of inter-group and intra-group variance was assessed, through Sum of Squares (SS) associated with a degree of freedom (df). The SS is a measure of spatial variations in temperature, while df takes into account sample size (Table 2). The Mean Squares (MS) for each source are given by the ratio SS/df. An F-Statistic is given for all MS, integrating the $\mathrm{df}$ associated with each term (inter- and intra-group). 
Table 2

Statistics associated with ANOVA.

\begin{tabular}{lllll}
\hline & SS & df & MS & F \\
\hline Between & SS(B) & k-1 & SS(B) & k-1 \\
Within & SS(W) & N-k & SS(W) \\
Total & SS(W) + SS(B) & N-1 & N-k & \\
\hline
\end{tabular}

$\mathrm{N}$ : Total sample size.

$\mathrm{k}$ : number of samples.

SS(B): Sum of squares between groups.

$\mathrm{SS}(\mathrm{W})$ : Sum of squares within groups.

\section{Results}

\subsection{Validation of WRF T2}

The WRF Domain 4 (Fig. 7d) and MUSTARDijon air temperatures were compared using the nearest neighbor, i.e. the 47 gridpoints containing a sensor. In the following, this spatial extraction of WRF grid-points is referred to as WRF47.

During the first three weeks of July 2015 (Fig. 8), WRF-simulated T2 shows a cold bias compared to the MUSTARDijon sensors, particularly at night (around $4{ }^{\circ} \mathrm{C}$ ). This temperature difference could be caused by spatial sampling: 47 sensors versus 13,050 gridpoints. In fact, MUSTARDijon deliberately oversamples the city and therefore also the plain, which is warmer than the plateau, where half of WRF Domain 4 is located. To test this hypothesis, the mean bias was recalculated using only the 47 grid-points of the WRF47. The cold bias was then reduced to $2-3{ }^{\circ} \mathrm{C}$, and fairly constant throughout the 24 -h cycle, with well-phased minimum and maximum values.

On 11 July 2015 in Dijon, sunrise was at 0355 UTC and sunset at 2136 UTC. Measured and simulated air temperatures were compared at four key times (Table 3): morning (0900 UTC), midday (maximum temperature, 1300 UTC), sunset (2000 UTC), and night (minimum temperature, 0400 UTC). As with the three-week period, WRF T2 underestimates temperature (Table 3). On average over the study area, this underestimation varies from $2.48{ }^{\circ} \mathrm{C}(0900 \mathrm{UTC})$ to $5.42^{\circ} \mathrm{C}(2000 \mathrm{UTC})$. For WRF47, the cold bias is less pronounced than for WRF T2 at $2000 \mathrm{UTC}\left(3.56^{\circ} \mathrm{C} / 5.42{ }^{\circ} \mathrm{C}\right)$ and $0400 \mathrm{UTC}\left(2.74{ }^{\circ} \mathrm{C} / 4.41{ }^{\circ} \mathrm{C}\right)$. Once the sampling effect is removed, the difference between simulations and observations is reduced. Nevertheless the cold bias of WRF47 remains strong (always $>2{ }^{\circ} \mathrm{C}$ ), particularly during night-time. Cold biases have been found in other cities for WRF simulations (e.g. Hu et al., 2010; Kusaka et al., 2012), but the bias here is particularly strong.

The spatial variance of temperature is much greater for WRF than for MUSTARDijon, but this difference could again be related to spatial sampling (Table 3). During daytime, the spatial variance for WRF47 is very close to the observed MUSTARDijon variance, while night-time variance remains much greater. The WRF T2 maps for the four key times (Fig. 9) present two clear patterns. During daytime (0900 and 1300 UTC), the T2 pattern is structured according to a west-east gradient controlled by altitude (Fig. 9a and b). The smaller-scale features clearly visible in the eastern part of Domain 4 correspond to water bodies. The cold islands formed by these water bodies suggest that daytime WRF T2 is highly sensitive to surface temperature. During night-time (2000 UTC and 0400 UTC), the T2 pattern is dominated by surface conditions, while the west-east temperature gradient is less noticeable (Fig. 9c and d). Built surface (Fig. 7d) and land use appear to be determining factors in the WRF T2 spatial pattern. As explained previously, WRF T2 is computed using classical similarity theory, which defines temperature gradient in the surface layer. The ground (or skin) temperature is used to solve the equation and compute the $2-\mathrm{m}$ temperature. This ground temperature is particularly dependent on the surface radiative budget, computed for each grid-point, and thus on the dominant land-use category of that grid-point. Moreover, due to the fact that it is parameterized, the 2-m temperature is not mixed in the horizontal plan by 3D turbulence.

Despite these biases, WRF T2 provides a coherent representation of the temporal rhythm and spatial features of the Dijon area.

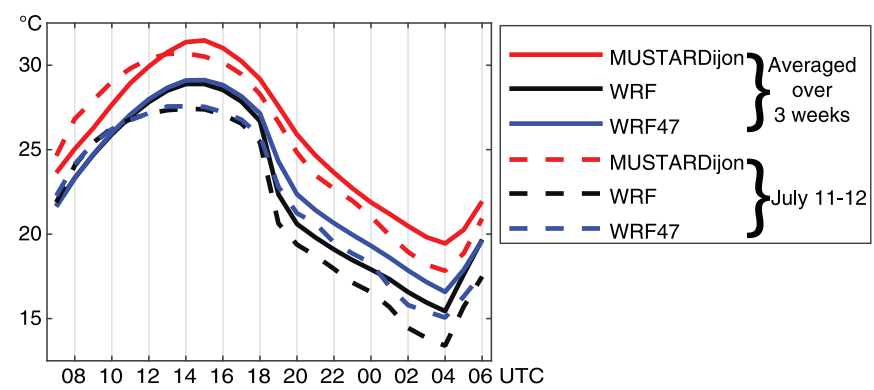

Fig. 8. Hourly temperature comparison for MUSTARDijon, WRF, and WRF47. 
Table 3

Average air temperature for the study area on July 11-12.

\begin{tabular}{|c|c|c|c|c|c|c|}
\hline \multicolumn{4}{|c|}{ Mean $\left({ }^{\circ} \mathrm{C}\right)$} & \multicolumn{3}{|l|}{ Variance $\left({ }^{\circ} \mathrm{C}^{2}\right)$} \\
\hline UTC & MUSTARDijon & WRF47 & WRF & MUSTARDijon & WRF47 & WRF \\
\hline 0900 & 27.90 & 25.40 & 25.42 & 0.38 & 0.45 & 1.27 \\
\hline 1300 & 30.65 & 27.56 & 27.34 & 0.53 & 0.53 & 1.40 \\
\hline 2000 & 24.80 & 21.24 & 19.38 & 1.23 & 3.12 & 3.43 \\
\hline 0400 & 17.80 & 15.06 & 13.39 & 0.71 & 3.90 & 2.40 \\
\hline
\end{tabular}

(a)

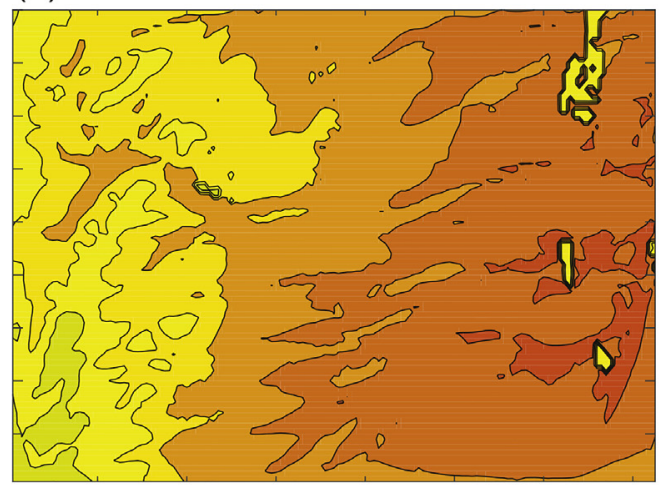

\section{(c)}

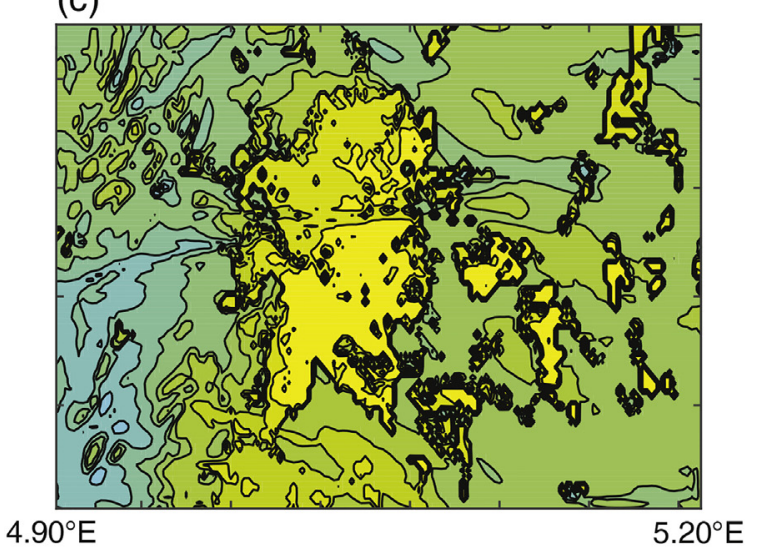

(b)

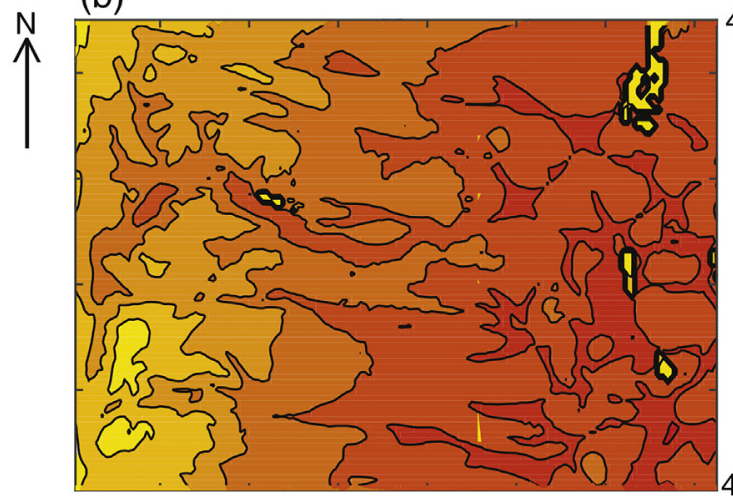

$47.38^{\circ} \mathrm{N}$ (d)

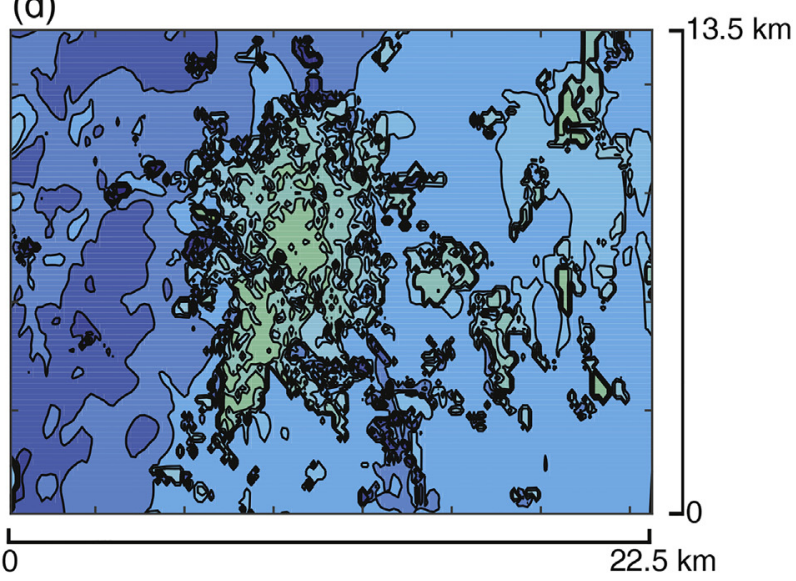

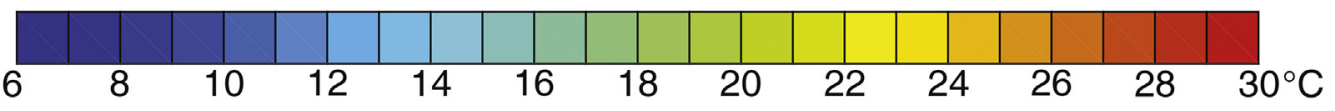

Fig. 9. WRF 2-m air temperature for 11-12 July 2015 at (a) 0900, (b) 1300, (c) 2000, and (d) 0400 UTC.

\subsection{Typologies and thermal environments}

On July 11-12, the diurnal temperature cycle measured by MUSTARDijon is well marked, with an average amplitude of about $13{ }^{\circ} \mathrm{C}$ (Fig. 10). At 0900 UTC and 1300 UTC, air temperatures are relatively homogeneous, regardless of typology or group. The coolest groups are LCZ5 (Open mid-rise), LCZD/104 (Low plants), UCZ7 (semi-rural development), and CLC_USGS5 (Cropland/ Grassland Mosaic). For all typologies, air temperature differs markedly between groups at sunset (2000 UTC), when the UHI sets in. These inter-group differences decrease until minimum air temperatures are reached, at sunrise (0400 UTC). At 2000 UTC, the warmest temperatures are observed in the most urbanized groups: LCZ2 (Compact mid-rise), UCZ2 (Intensely developed-High density), and CLC_USGS32 (High Intensity Residential).

In order to compare inter-group and intra-group variance visually, boxplots are presented for each typology and each group. Intragroup variance can only be observed when the group is composed of several sensors. Boxplots in Fig. 11 relate to NDVI and LST values obtained by Landsat 8 at 1030 UTC; in Fig. 12 to air temperature measured in situ with the MUSTARDijon network; and in Fig. 13 to T2 temperature simulated by WRF. 


\begin{tabular}{|c|c|c|c|c|c|c|c|}
\hline & h UTC & 0900 & 1300 & 2000 & 0400 & 24 hours & $\begin{array}{l}\text { MUSTARDijon } \\
\text { mean } \mathrm{T}^{\circ}\end{array}$ \\
\hline MUSTARDijon & Sensors & 27.93 & 30.67 & 24.83 & 17.83 & 25.16 & $\mathrm{~T}^{\circ} \mathrm{C}$ \\
\hline LCZ2 & 7 & 28.12 & 31.05 & 25.73 & 18.78 & 25.75 & \\
\hline LCZ3 & 8 & 28.31 & 31.08 & 25.11 & 17.96 & 25.41 & \\
\hline LCZ4 & 9 & 27.64 & 30.29 & 24.60 & 17.78 & 24.93 & \\
\hline LCZ5 & 2 & 26.95 & 29.73 & 23.10 & 16.70 & 23.95 & MUSTARDij \\
\hline LCZ6 & 2 & 28.74 & 31.63 & 25.63 & 17.98 & 25.73 & \\
\hline LCZ8 & 6 & 27.76 & 30.33 & 25.40 & 18.08 & 25.32 & $08<\mathrm{T}<12$ \\
\hline LCZ9 & 5 & 28.21 & 30.79 & 24.44 & 17.29 & 24.96 & $0.0<1=1.2$ \\
\hline LCZ104 & 4 & 27.28 & 30.26 & 23.38 & 16.83 & 24.34 & $-0.4 \leq T \leq 0.4$ \\
\hline UCZ2 & 3 & 28.33 & 31.26 & 25.95 & 19.10 & 25.99 & $-0.8 \leq T<-0.4$ \\
\hline UCZ3 & 14 & 28.10 & 30.92 & 25.17 & 18.21 & 25.43 & $-1.2 \leq \mathrm{T}<-0.8$ \\
\hline UCZ4 & 6 & 27.76 & 30.33 & 25.40 & 18.08 & 25.32 & $\mathrm{~T}^{\circ} \mathrm{C}<-1$ \\
\hline UCZ5 & 6 & 28.04 & 30.83 & 24.48 & 17.89 & 25.13 & \\
\hline UCZ6 & 4 & 28.08 & 30.84 & 25.59 & 17.92 & 25.40 & \\
\hline UCZ7 & 7 & 27.26 & 29.68 & 23.48 & 16.60 & 24.01 & \\
\hline CLC_USGS5 & 6 & 27.20 & 29.77 & 22.88 & 16.67 & 24.06 & \\
\hline CLC_USGS32 & 4 & 28.34 & 31.22 & 25.96 & 18.98 & 25.95 & \\
\hline CLC_USGS31 & 22 & 28.11 & 30.85 & 24.91 & 17.86 & 25.24 & \\
\hline CLC_USGS33 & 12 & 27.79 & 30.61 & 25.49 & 18.02 & 25.33 & \\
\hline
\end{tabular}

Fig. 10. Hourly air temperature for 11 July 2015 at 0900 UTC, 1300 UTC, 2000 UTC, and 12 July 2015 at 0400 UTC. Values: MUSTARDijon mean temperature and temperature for each group (LCZ, UCZ, and CLC_USGS). Color: deviation from MUSTARDijon mean temperature.

(a)

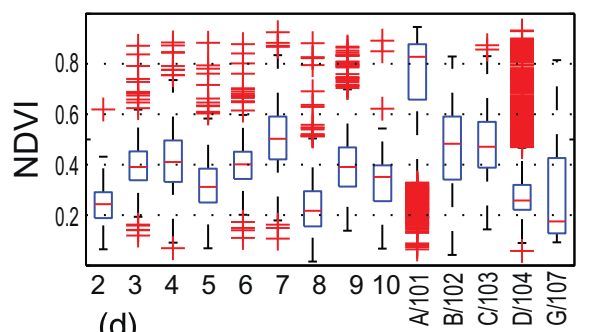

(d)

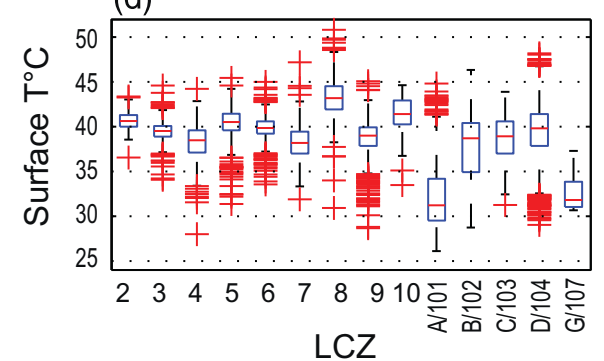

(b)

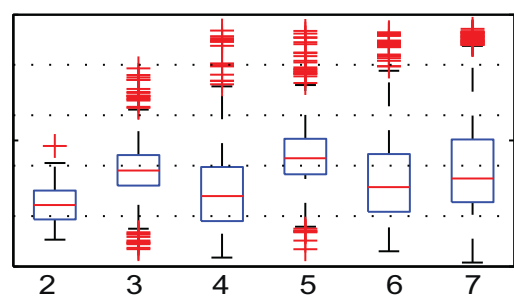

(e)

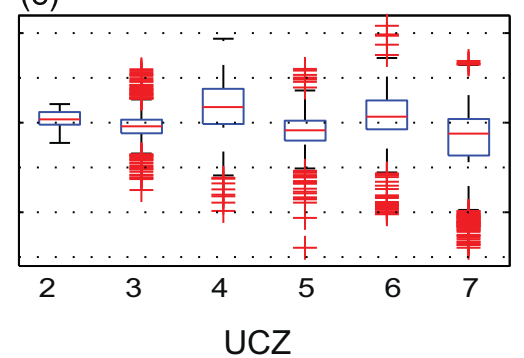

(c)

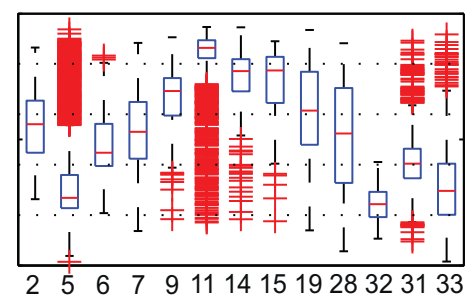

(f)

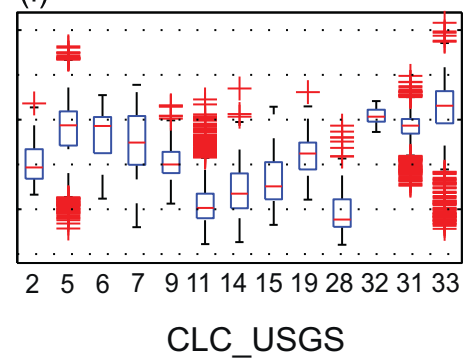

Fig. 11. Boxplots for NDVI (a, b, and c), and Landsat 8 Surface Temperature (d, e, and f), on 11 July 2015, at 1030 UTC; for LCZ (a and d), UCZ (b and e), and CLC_USGS (c and f). Red bar: median; box: inter-quartile range (from 25th to 75th percentile); whiskers: data range; red plus signs: statistical outliers ( $>1.5$ times the inter-quartile range). See Fig. 3 for description of groups. (For interpretation of the references to color in this figure legend, the reader is referred to the web version of this article.)

For NDVI and LST (Fig. 11), inter-group variance is not clearly differentiated for UCZ (Fig. 11b and e), but is much greater for CLC_USGS (Fig. 11c and f). For example, CLC_USGS5 (Cropland/Grassland Mosaic) is particularly warm for a rural group (Fig. 11f), with low NDVI values (Fig. 11c). This result can be explained because the crops had already been harvested there. The most precise information about agricultural and forest areas is provided by CLC_USGS, which is therefore the most efficient tool for differentiating LULC groups on the basis of NDVI (Fig. 11c).

For LCZ (Fig. 11a and d), LCZ8 (Large low-rise) presents the lowest values for NDVI (except for water) and the highest for LST, corresponding to industrial or recent tertiary areas, also observed for UCZ4 (Fig. 11e). This is a feature of the SUHI signature during daytime (Dousset et al., 2011). However, urban groups (LCZ 2-10 and UCZ 2-6) are only slightly warmer than rural groups (LCZ A/ 
(a)

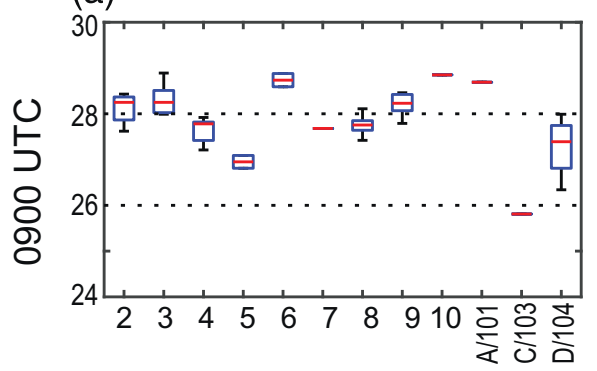

(d)

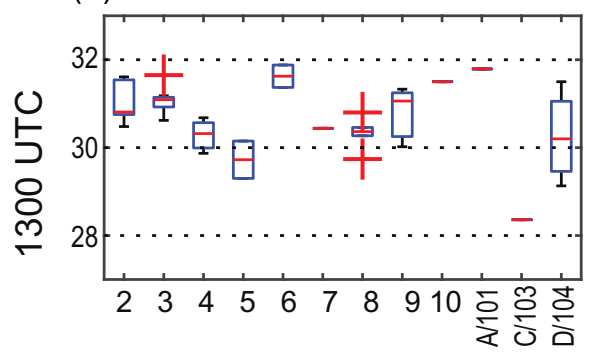

(g)

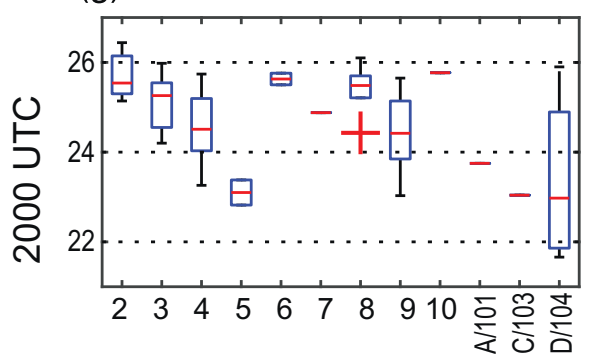

(j)

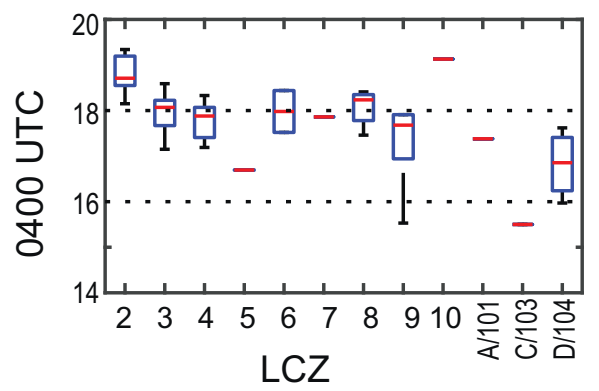

(b)

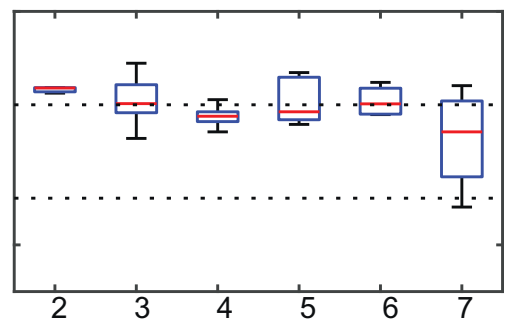

(e)

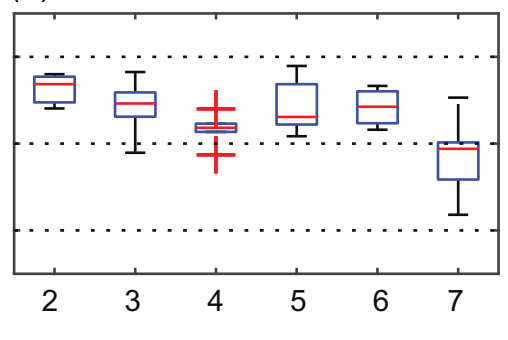

(h)

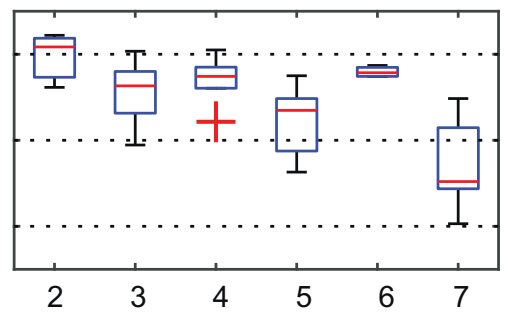

(k)

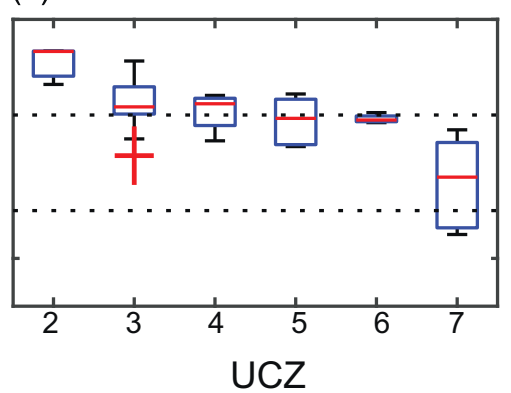

(c)

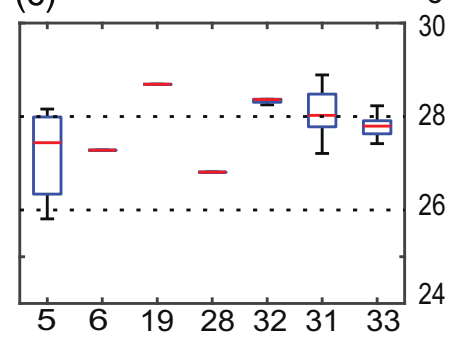

(f)

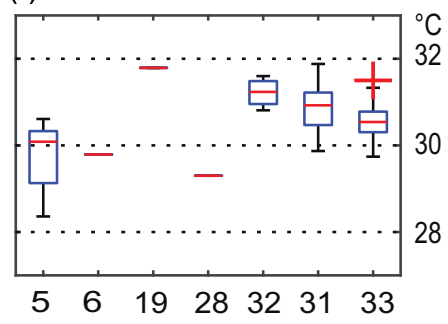

(i)

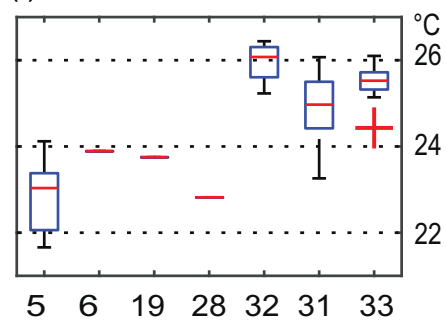

(I)

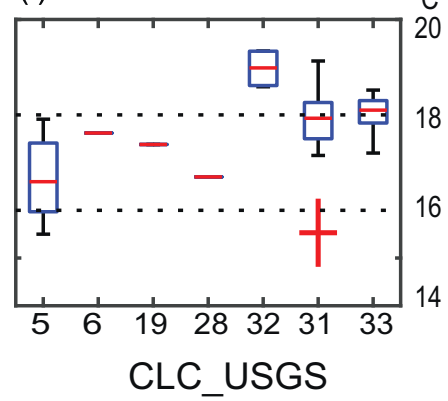

Fig. 12. Boxplots for MUSTARDijon Air Temperature at 0900 UTC (a, b, and c), 1300 UTC (d, e, and f), 2000 UTC (g, h, and i), and 0400 UTC (j, k, and l); for LCZ (a, d, g, and j), UCZ (b, e, h, and k), and CLC_USGS (c, f, i, and l). See Fig. 3 for description of groups.

101-G/107 and UCZ7). The LCZ typology (and to a lesser extent UCZ) provides a more detailed account of built surfaces than the CLC_USGS tool.

The MUSTARDijon air temperatures are presented in Fig. 12. Within the UCZ typology, 7 out of the 47 sensors remain nonclassified (Fig. 3b). When the sample is large enough (e.g., UCZ7), intra-group differences may be strong (Fig. 12b, e, h, and k). For groups documented by a single sensor (LCZ7, 10, A/101 and C/103, or CLC_USGS6, 19 and 28) intra-group comparison is impossible (Fig. 12). For small samples (2 to 10 sensors per group), caution is required when comparing intra-group variance. Night-time temperatures (2000 and 0400 UTC) generally show strong heterogeneity. The most urbanized groups (LCZ2, UCZ2, and CLC_USGS32) present the highest night-time temperatures. During daytime (0900 and 1300), for UCZ and CLC_USGS, the same groups still present the highest temperatures, but for LCZ the highest temperature is observed for LCZ6 (Open low-rise). There are more urban groups in the LCZ typology than in UCZ. The MUSTARDijon temperatures vary from one LCZ group to another, while 
(a)

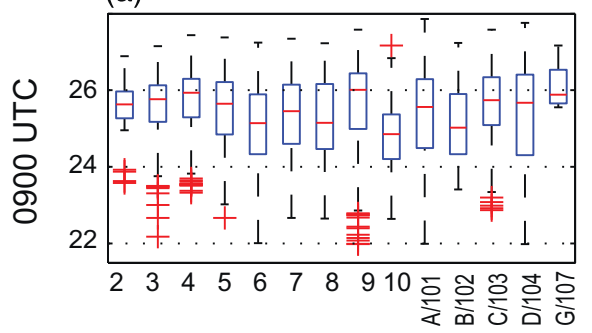

(d)

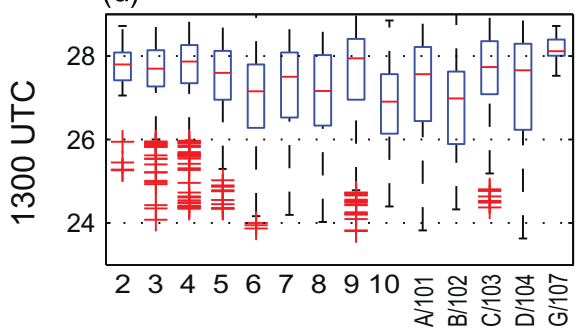

(g)

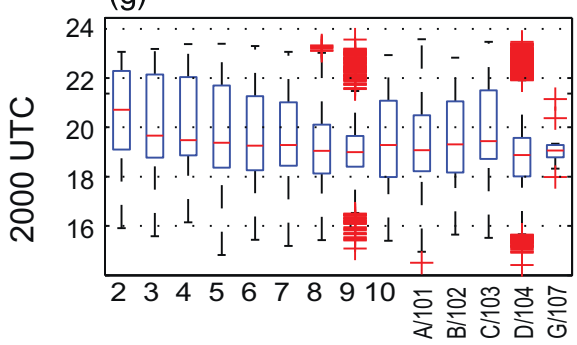

(j)

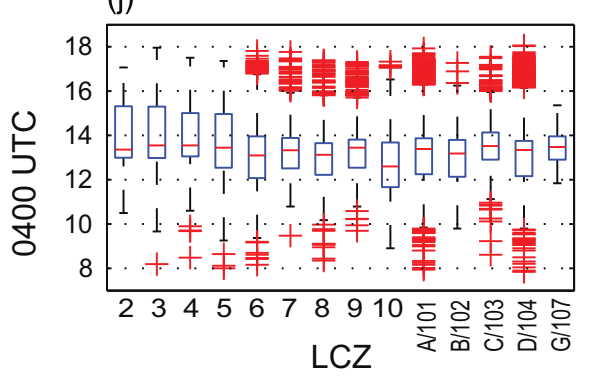

(b)

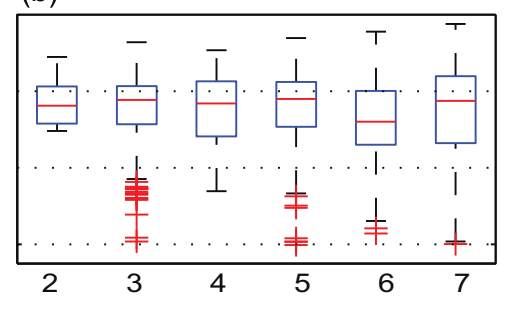

(e)

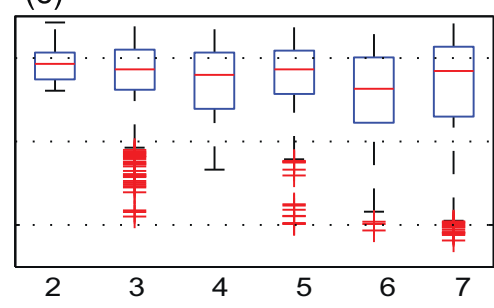

(h)

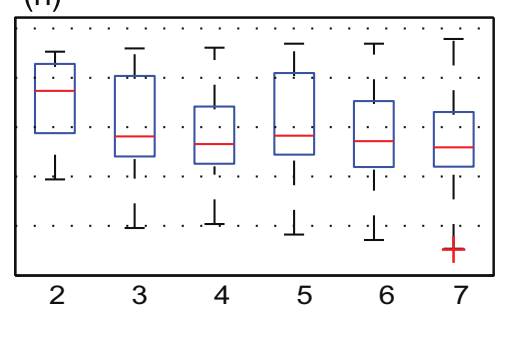

(k)

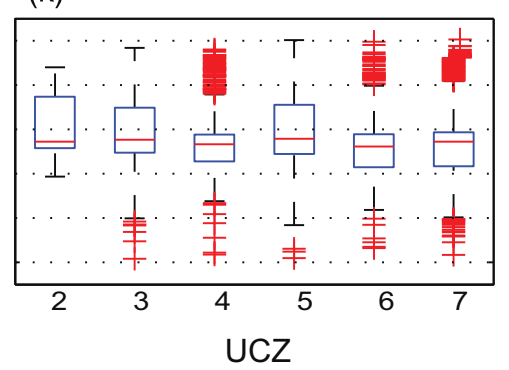

(c)

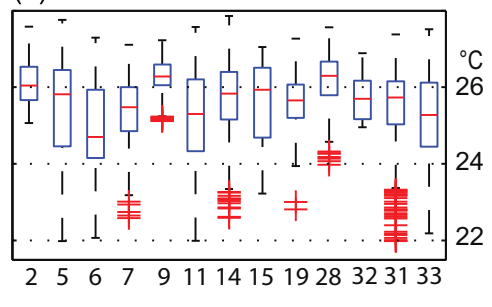

(f)

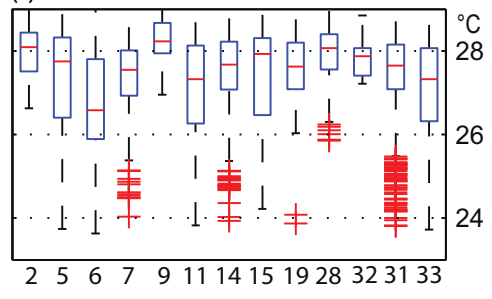

Fig. 13. As in Fig. 12, with data for WRF T2. See Fig. 3 for description of groups.

intra-class variation is limited, thus confirming the validity of the LCZ typology for a medium-sized European city.

The large number of grid-points $(13,050)$ in the WRF simulations provides a more robust study of intra-group heterogeneity (Fig. 13). Intra-group heterogeneity is time-dependent, and generally greatest at sunset (2000 UTC). Boxplots for WRF47 are not shown, as some of the groups contain few grid-points. The ANOVA, however, provides additional information on this issue through the use of significance tests.

Boxplots allow visual assessment of the specificities of each typology, and each environmental variable. In order to further quantify the respective weight of intra-group and inter-group variances, and to rank them, a set of ANOVA tests is run for each of the typologies, for the MUSTARDijon and WRF air temperatures, and for each hour of the 24-h period, July 11-12 (Fig. 14). The Mean Squares (MS) are used to quantify variations in thermal environment both between and within groups (Fig. 14a, c, and e). The FStatistics document the statistical significance of the inter-group to intra-group variance ratio). This ratio is seen as an indicator of the capacity of the three typologies to differentiate between groups, while forming homogeneous groups in terms of thermal environment (Fig. 14b, d, and f).

Inter-group variation is stronger than intra-group variation (Fig. 14a, c and e), whatever the typology, for MUSTARDijon (Fig. 14a), the whole WRF simulation domain (Fig. 14c), and for WRF47 (Fig. 14e), whatever the hour. These variations are relatively stationary during daytime until 1800 UTC, and increase suddenly at 1900 UTC, just before sunset (Fig. 14a, c, and e). This sudden increase is especially strong at the inter-group scale. It is visible in MUSTARDijon (Fig. 14a), but stronger in WRF and WRF47 
(a)
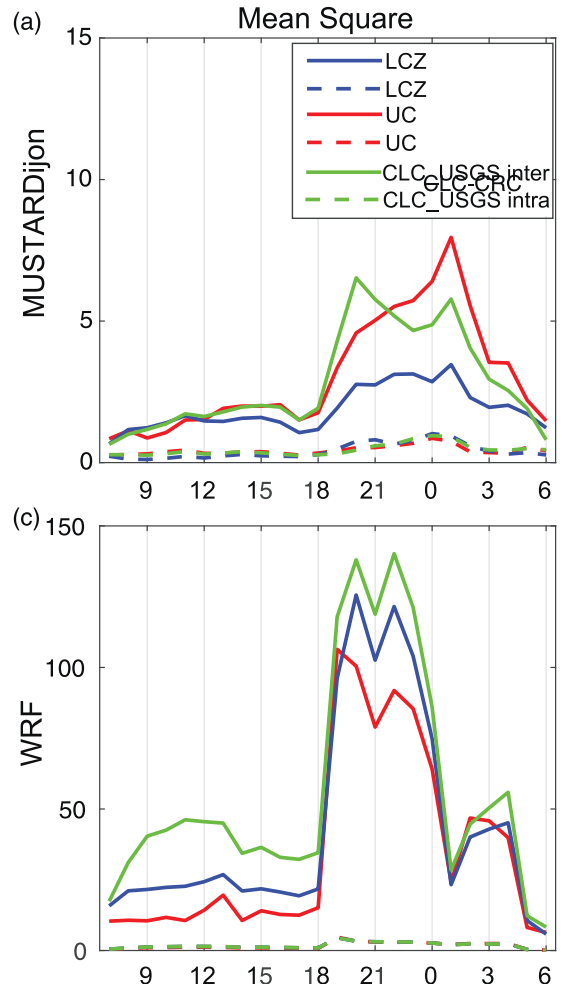

(e)

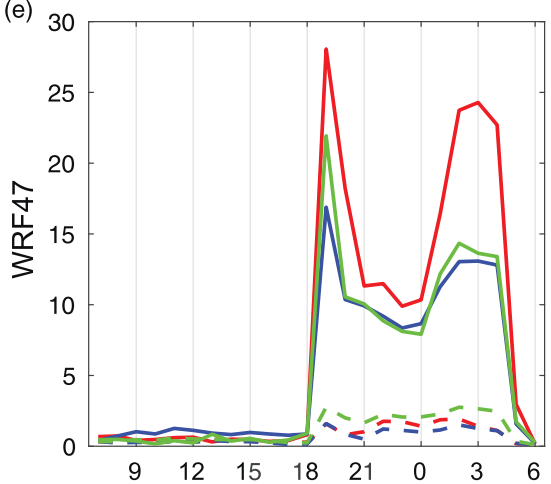

(b)

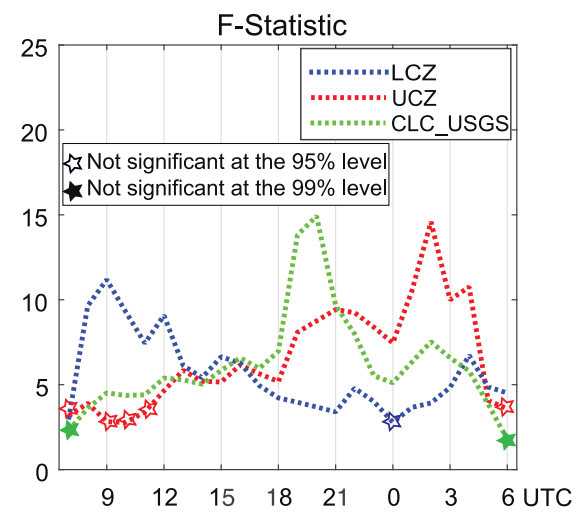

(d)

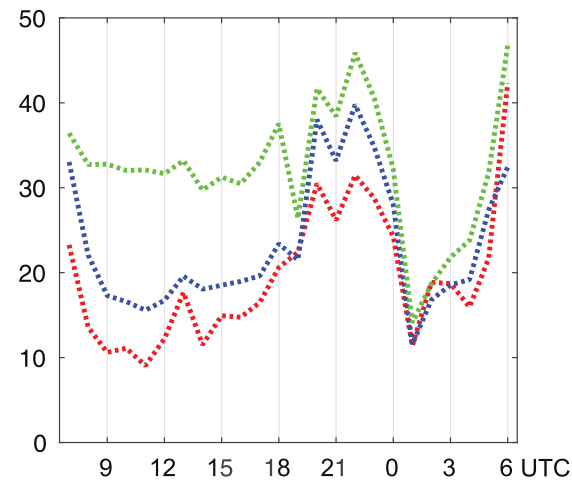

(f)

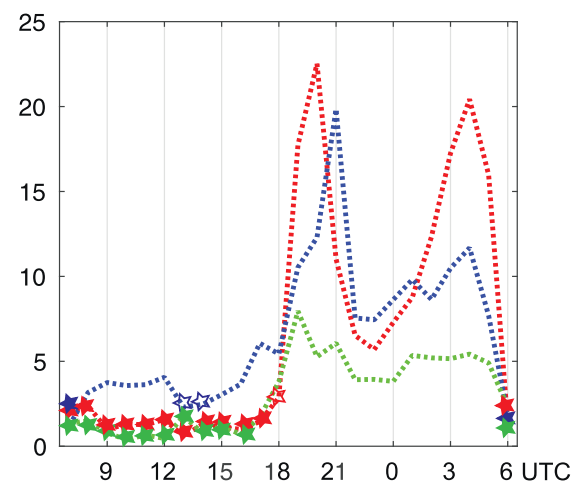

Fig. 14. Inter-group versus intra-group variance depicted by ANOVA. Mean Squares (MS) for (a) MUSTARDijon air temperature, (c) WRF T2, and (e) WRF47 T2. Associated F-Statistic for (b) MUSTARDijon air temperature, (d) WRF T2, and (f) WRF47 T2.

(Fig. 14c and e). Curious features are the premature decrease in inter-group variance at 0100 UTC for WRF (Fig. 14c), and the brevity of the variance peak at 1900 UTC for WRF47 (Fig. 14e).

For MUSTARDijon (Fig. 14b) and WRF47 (Fig. 14f), significance depends on typology and hour. For MUSTARDijon (Fig. 14b), differences between inter-group and intra-group variances are significant at $99 \%$ for LCZ, with only one exception (95\% at 0000 UTC). For UCZ and CLC_USGS, non-significant values are more frequent. For WRF47 (Fig. 14f), the 99\% significance bound is systematically reached during night-time (from 1900 to 0500 UTC). Results must be considered with more caution during daytime. In some cases, inter-group variance is not significantly stronger than intra-group variance. The typology that gives the greatest number of significant results is LCZ, particularly for WRF47 (Fig. 14f). For WRF, differences between inter-group and intra-group variances are systematically significant (Fig. 14d).

As CLC_USGS is coupled with WRF, some results may not be completely independent (Fig. 13, and Fig. 14c, d, e, and f). Perhaps for this reason, boxplots and ANOVA for WRF T2 give better results for CLC_USGS than for UCZ or LCZ. In fact, the CLC_USGS-WRF coupling is likely to contribute to the excellent performance of CLC_USGS (Fig. 14c and d). Nevertheless, when the sample size is reduced (Fig. 14e and f), the performance of UCZ and that of LCZ are better than that of CLC_USGS. The problem of circularity does not affect the analysis of variables from Landsat8 or MUSTARDijon (Figs. 11, 12, and 14a and b). As the ANOVA levels of significance take group size into account, it is clear that LCZ has the best capacity to identify the most homogeneous groups in terms of thermal environment. 


\section{Discussion and conclusion}

This case study, carried out in a medium-sized European city (Dijon, eastern France), on a summer day favorable to the development of a UHI, quantifies to what extent LCZ, UCZ, and CLC_USGS are relevant to analyze and discriminate the spatial structures of surface and air temperatures. Air temperature patterns are strongly determined by group. This is true during daytime, even though group is a second-order parameter, after the first-order topographic parameter. This is even more true during night-time, when group is the first-order parameter, denoting a reversal in the parameters explaining the spatial organization of the temperature field. Thus, both typologies are relevant for urban areas to (i) select sites for the implementation of in situ measurements, (ii) perform zoning on maps made from satellite products, and (iii) prescribe surface conditions for climate modeling. They are also useful input keys when interacting with developers and urban planners seeking to control summer temperature extremes, which are directly associated with urban surface geometry and thermal properties.

What are the strengths and weaknesses of each of these typologies? For the CLC_USGS tool, data can be obtained from the CLC database, as is the case for all European cities. For urban climate studies, CLC data must be associated with an accurate, highresolution, built-surface database, e.g. BD TOPO for France, or OpenStreetmap data products for all countries (for a comparison between the two, see Girres and Touya, 2010). The CLC_USGS tool is efficient at differentiating rural from urban air temperatures, and even better to differentiate between rural groups. It would be possible to create tools equivalent to CLC_USGS throughout Europe, or wherever databases similar to CLC exist. However, the limit of three urban groups (imposed by WRF) provides insufficient detail for planners and developers about the many types of urban environment. The UCZ typology performs well when maximizing intergroup variance, especially in urban areas, but it cannot be applied to rural environments. The LCZ typology is applicable worldwide, in both rural and urban environments, and could be very useful in selecting zones to be instrumented when developing urban temperature networks. It gives good results with respect to the thermal coherence of its groups. Indeed, even for level 0, the fine LCZ partitioning leads to a multiplication of groups, a very interesting feature for urban planners. However, it does not necessarily correspond to the UHI pattern, which is often smoothed.

The typologies were compared using several environmental variables (NDVI, surface temperature, and air temperature). This comparison is however limited to the study of a single diurnal cycle. One potential perspective will be to analyze the temporal variability of spatial temperature patterns and gradients. Further simulations will be performed to try to understand and perhaps reduce the WRF cold bias. To that end, as in Madrid (Brousse et al., 2016), we propose to prescribe LCZ to WRF. Finally, taking into account major public health issues, attention should be focused on recent summer heat waves, for which we now have in situ measurements from the MUSTARDijon network.

\section{Acknowledgments}

The Agence De l'Environnement et de la Maîtrise de l'Energie (ADEME) Bourgogne Franche-Comté, Dijon Métropole, Météo France, and the Centre de Calcul de l'université de Bourgogne (CCuB) are thanked for financial and technical support.

\section{References}

Arnfield, A.J., 2003. Two decades of urban climate research: a review of turbulence, exchanges of energy and water, and the urban heat island. Int. J. Climatol. 23, 1-26. https://doi.org/10.1002/joc.859.

Azevedo, J.A., Chapman, L., Muller, C.L., 2016. Quantifying the daytime and night-time urban heat island in Birmingham, UK: A comparison of satellite derived land surface temperature and high resolution air temperature observations. Remote Sens. 8, 153.

Baumüller, J., 2015. A summary of key methodologies, in: The Urban Climatic Map: A Methodology for Sustainable Urban Planning. pp. 35-44.

Bechtel, B., Daneke, C., 2012. Classification of local climate zones based on multiple earth observation data. IEEE J. Sel. Top. Appl. Earth Obs. Remote Sens. 5, 1191-1202.

Bechtel, B., Foley, M., Mills, G., Ching, J., See, L., Alexander, P., O'Connor, M., Albuquerque, T., de Fatima Andrade, M., Brovelli, M., 2015. CENSUS of Cities: LCZ Classification of Cities (Level 0)-Workflow and Initial Results from Various Cities.

Bechtel, B., Pesaresi, M., See, L., Mills, G., Ching, J., Alexander, P.J., Feddema, J.J., Florczyk, A.J., Stewart, I., 2016. Towards consistent mapping of urban structureglobal human settlement layer and local climate zones. ISPRS-Int. Arch. Photogramm. Remote Sens. Spat. Inf. Sci. 41, 1371-1378.

Brousse, O., Martilli, A., Foley, M., Mills, G., Bechtel, B., 2016. WUDAPT, an efficient land use producing data tool for mesoscale models? Integration of urban LCZ in WRF over Madrid. Urban Clim. 17, 116-134.

Büttner, G., Feranec, J., Jaffrain, G., 2002. Corine Land Cover update 2000-Technical guidelines [I\&CLC2000 project] (No. 89). European Environment Agency, Copenhagen.Chandler, T.J., 1962. London's urban climate. Geogr. J. 128, 279-298.

Chandler, T.J., 1962. London's urban climate. The Geographical Journal 128 (3), 279-298 (Sep).

Chen, F., Kusaka, H., Bornstein, R., Ching, J., Grimmond, C.S.B., Grossman-Clarke, S., Loridan, T., Manning, K.W., Martilli, A., Miao, S., others, 2011. The integrated WRF/urban modelling system: development, evaluation, and applications to urban environmental problems. Int. J. Climatol. 31, $273-288$.

Conrad, O., Bechtel, B., Bock, M., Dietrich, H., Fischer, E., Gerlitz, L., Wehberg, J., Wichmann, V., Böhner, J., 2015. System for automated geoscientific analyses (SAGA) v. 2.1.4. Geosci. Model Dev. 8, 1991-2007.

Davenport, A.G., Grimmond, C.S.B., Oke, T.R., Wieringa, J., 2000. Estimating the roughness of cities and sheltered country, in: Proceedings. In: 12th Conference on Applied Climatology. American Meteorological Society, Boston, Asheville, NC, pp. 96-99.

De Lapparent, B., Roux, J., Richard, Y., Pohl, B., Bientz, S., Codet-Hache, O., Dumaitre, F., Toussaint, H., Tissot, A.-C., Thévenin, D., others, 2015. Mesures de la température et spatialisation de l'Ilot de Chaleur Urbain à Dijon. In: 28ème Colloque de l'Association Internationale de Climatologie. Association Internationale de Climatologie, pp. 257-262.

Dee, D.P., Uppala, S.M., Simmons, A.J., Berrisford, P., Poli, P., Kobayashi, S., Andrae, U., Balmaseda, M.A., Balsamo, G., Bauer, P., others, 2011. The ERA-Interim reanalysis: Configuration and performance of the data assimilation system. Q. J. R. Meteorol. Soc. 137, 553-597.

Dousset, B., Gourmelon, F., Laaidi, K., Zeghnoun, A., Giraudet, E., Bretin, P., Mauri, E., Vandentorren, S., 2011. Satellite monitoring of summer heat waves in the Paris metropolitan area. Int. J. Climatol. 31, 313-323.

Dudhia, J., 1989. Numerical study of convection observed during the winter monsoon experiment using a mesoscale two-dimensional model. J. Atmos. Sci. 46, 3077-3107. 
Emery, J., Dudek, J., Granjon, L., Pohl, B., Richard, Y., Thevenin, T., Martiny, N., 2018. Characterizing Urban Morphology for Urban Climate Simulation Based on a GIS Approach, in: Nicolas Baghdadi, Clément Mallet, Mehrez Zribi (dir.), QGIS and Applications in Territorial Planning, ISTE éditions, Collections Earth Systems Environmental Sciences. pp. 53-92 (ISBN: (978-1-78630-189-5).

Emmanuel, R., Krüger, E., 2012. Urban heat island and its impact on climate change resilience in a shrinking city: the case of Glasgow, UK. Build. Environ. 53, $137-149$.

Feddema, J., Mills, G., Ching, J., 2015. Demonstrating the Added Value of WUDAPT for Urban Climate Modelling. 9th ICUC Toulouse Fr.Demonstrating the Added Value of WUDAPT for Urban Climate Modelling. 9th ICUC Toulouse Fr.

Gál, T., Bechtel, B., Unger, J., 2015. Comparison of two different Local Climate Zone mapping methods.

Giffinger, R., Fertner, C., Kramar, H., Meijers, E., others, 2007. City-ranking of European medium-sized cities. Cent. Reg. Sci. Vienna UT 1-12.

Giorgi, F., 1990. Simulation of regional climate using a limited area model nested in a general circulation model. J. Clim. 3, $941-963$.

Girres, J.-F., Touya, G., 2010. Quality assessment of the French OpenStreetMap dataset. Trans. GIS 14, 435-459.

Grimmond, C.S.B., Oke, T.R., 1999. Aerodynamic properties of urban areas derived from analysis of surface form. J. Appl. Meteorol. 38, $1262-1292$.

Hagolle, O., Huc, M., Villa Pascual, D., Dedieu, G., 2015. A multi-temporal and multi-spectral method to estimate aerosol optical thickness over land, for the atmospheric correction of formosat-2, Landsat, venus and Sentinel-2 images. Remote Sens. 7, 2668-2691.

Hong, S.-Y., Noh, Y., Dudhia, J., 2006. A new vertical diffusion package with an explicit treatment of entrainment processes. Mon. Weather Rev. 134, 2318-2341.

Houet, T., Pigeon, G., 2011. Mapping urban climate zones and quantifying climate behaviors-An application on Toulouse urban area (France). Environ. Pollut. 159, $2180-2192$.

Hu, X.-M., Nielsen-Gammon, J.W., Zhang, F., 2010. Evaluation of three planetary boundary layer schemes in the WRF model. J. Appl. Meteorol. Climatol. 49, $1831-1844$.

IGN, 2016. Description of BD TOPO 2.1 (in French: Descriptif de contenu, octobre 2011). Saint Mandé. http://professionnels.ign.fr/sites/default/files/DC_BDTOPO_2_ 1.pdf.

Joly, D., Brossard, T., Cardot, H., Cavailhes, J., Hilal, M., Wavresky, P., 2010. Les types de climats en France, une construction spatiale. Cybergeo Eur. J. Geogr. https://doi.org/10.4000/cybergeo.23155. http://cybergeo.revues.org/23155.

Kain, J.S., 2004. The Kain-Fritsch convective parameterization: an update. J. Appl. Meteorol. 43, 170-181.

Kottek, M., Grieser, J., Beck, C., Rudolf, B., Rubel, F., 2006. World map of the Köppen-Geiger climate classification updated. Meteorol. Z. 15, $259-263$.

Kourtidis, K., Georgoulias, A.K., Rapsomanikis, S., Amiridis, V., Keramitsoglou, I., Hooyberghs, H., Maiheu, B., Melas, D., 2015. A study of the hourly variability of the urban heat island effect in the Greater Athens Area during summer. Sci. Total Environ. 517, 162-177.

Kusaka, H., Kondo, H., Kikegawa, Y., Kimura, F., 2001. A simple single-layer urban canopy model for atmospheric models: comparison with multi-layer and slab models. Boundary-Layer Meteor. 101, 329-358.

Kusaka, H., Hara, M., Takane, Y., 2012. Urban climate projection by the WRF model at 3-km horizontal grid increment: dynamical downscaling and predicting heat stress in the 2070's August for Tokyo, Osaka, and Nagoya metropolises. J. Meteorol. Soc. Jpn. Ser II 90, 47-63.

Lau, K.K.-L., Ren, C., Shi, Y., Zheng, V., Yim, S., Lai, D., 2015. Determining the optimal size of local climate zones for spatial mapping in high-density cities. (9th ICUC Toulouse Fr).Determining the optimal size of local climate zones for spatial mapping in high-density cities. (9th ICUC Toulouse Fr).

Leconte, F., Bouyer, J., Claverie, R., Pétrissans, M., 2015a. Estimation of Spatial Air Temperature Distribution at Sub-Mesoclimatic Scale Using the LCZ Scheme and Mobile Measurements.

Leconte, F., Bouyer, J., Claverie, R., Pétrissans, M., 2015b. Using local climate zone scheme for UHI assessment: evaluation of the method using mobile measurements. Build. Environ. 83, 39-49.

Leconte, F., Bouyer, J., Claverie, R., Pétrissans, M., 2016. Analysis of nocturnal air temperature in districts using mobile measurements and a cooling indicator. Theor. Appl. Climatol. 1-12.

Lehnert, M., Geletič, J., Husák, J., Vysoudil, M., 2015. Urban field classification by “local climate zones” in a medium-sized Central European city: the case of Olomouc (Czech Republic). Theor. Appl. Climatol. 122, 531-541. https://doi.org/10.1007/s00704-014-1309-6.

Lemonsu, A., Masson, V., 2002. Simulation of a summer urban breeze over Paris. Bound.-Layer Meteorol. 104, 463-490.

Mills, G., Ching, J., See, L., Bechtel, B., Foley, M., 2015. An introduction to the WUDAPT project, in: 9th International Conference on Urban Climate. (Toulouse).

Mlawer, E.J., Clough, S.A., 1997. On the extension of rapid radiative transfer model to the shortwave region, in: Proceedings of the 6th Atmospheric Radiation Measurement (ARM) Science Team Meeting, US Department of Energy, CONF-9603149.

Oke, T.R., 2006. Initial Guidance to Obtain Representative Meteorological Observations At Urban Sites. World Meteorological Organization, Instruments and Observing Methods (Report No). 81.

Ouzeau, G., Soubeyroux, J.-M., Schneider, M., Vautard, R., Planton, S., 2016. Heat waves analysis over France in present and future climate: application of a new method on the EURO-CORDEX ensemble. Clim. Serv. 4, 1-12.

Perera, N.G.R., Emmanuel, R., 2016. A "Local Climate Zone" based approach to urban planning in Colombo, Sri Lanka. Urban Clim. https://doi.org/10.1016/j.uclim. 2016.11.006.

Schoetter, R., Cattiaux, J., Douville, H., 2015. Changes of western European heat wave characteristics projected by the CMIP5 ensemble. Clim. Dyn. 45, $1601-1616$. Skamarock, W.C., Coauthors, 2008. A description of the advanced research WRF version 3. NCAR Tech. Note. In: NCAR/TN-475+ STR.

Sobrino, J.A., Jiménez-Muñoz, J.C., Paolini, L., 2004. Land surface temperature retrieval from LANDSAT TM 5. Remote Sens. Environ. 90, 434-440.

Sobrino, J.A., Jiménez-Muñoz, J.C., Sòria, G., Romaguera, M., Guanter, L., Moreno, J., Plaza, A., Martínez, P., 2008. Land surface emissivity retrieval from different VNIR and TIR sensors. IEEE Trans. Geosci. Remote Sens. 46, 316-327.

Stewart, I.D., 2007. Landscape representation and the urban-rural dichotomy in empirical urban heat island literature, 1950-2006. Acta Climatol. Chorol. 40, $111-121$.

Stewart, I.D., 2011. A systematic review and scientific critique of methodology in modern urban heat island literature. Int. J. Climatol. 31, 200-217.

Stewart, I.D., Oke, T.R., 2012. Local climate zones for urban temperature studies. Bull. Am. Meteorol. Soc. 93, 1879-1900.

Tewari, M., Chen, F., Wang, W., Dudhia, J., Lemone, M.A., Mitchell, K., Ek, M., Gayno, G., Wegiel, J., Cuenca, R.H., 2004. Implementation and verification of the unified NOAH land surface model in the WRF model. In: 20th Conference On Weather Analysis and Forecasting/16th Conference on Numerical Weather Prediction, pp. 11-15. http://www2.mmm.ucar.edu/wrf/users/phys_refs/LAND_SURFACE/noah.pdf.

Thierry, X., 2015. Luc Brière, Suvani Vugdalic (dir.), La France et ses territoires, Paris, Insee références, 2015,172 p. Population 70, 879-881.

Van Hove, L.W.A., Jacobs, C.M.J., Heusinkveld, B.G., Elbers, J.A., Van Driel, B.L., Holtslag, A.A.M., 2015. Temporal and spatial variability of urban heat island and thermal comfort within the Rotterdam agglomeration. Build. Environ. 83, 91-103.

Vandentorren, S., Suzan, F., Medina, S., Pascal, M., Maulpoix, A., Cohen, J.-C., Ledrans, M., 2004. Mortality in 13 French cities during the August 2003 heat wave. Am. J. Public Health 94, 1518-1520.

Wahl, L., Paul, P., Pichard, C., Mory, N., Drogue, G., Pfister, L., 2005. Les canicules de l'été 2003: un événement météorologique exceptionnel dans le quart nord-est de la France. Rev. Géographique Est 45, 67-77.

Wang, R., Ren, C., Xu, Y., Ka-Lun Lau, K., Shi, Y., 2018. Mapping the local climate zones of urban areas by GIS-based and WUDAPT methods: A case study of Hong Kong. Urban Clim. 24, 567-576.

Willett, K.M., Sherwood, S., 2012. Exceedance of heat index thresholds for 15 regions under a warming climate using the wet-bulb globe temperature. Int. J. Climatol. 32, 161-177. https://doi.org/10.1002/joc.2257.

Zhang, D., Anthes, R.A., 1982. A high-resolution model of the planetary boundary layer: sensitivity tests and comparisons with SESAME-79 data. J. Appl. Meteorol. 21, 1594-1609.

Zheng, Y., Ren, C., Xu, Y., Wang, R., Ho, J., Lau, K., Ng, E., 2018. GIS-based mapping of Local Climate Zone in the high-density city of Hong Kong. Urban Clim. 24, 419-448. 